\title{
The Impact of Promotional Activities and Inflationary Trends on a Deteriorated Inventory Model Allowing Delay in Payment
}

\author{
Bhanupriya Dash $^{1}$, Monalisha Pattnaik ${ }^{2, *}$, Hadibandhu Pattnaik ${ }^{3}$ \\ ${ }^{1}$ Lecturer in Mathematics, Kamala Nehru Womens' College, Bhubaneswar \\ ${ }^{2}$ Department of Business Administration, Utkal University, Bhubaneswar, India \\ ${ }^{3}$ Department of Mathematics, KIIT University, Bhubaneswar \\ *Corresponding author: monalisha_1977@yahoo.com
}

Received August 22, 2014; Revised August 25, 2014; Accepted August 26, 2014

\begin{abstract}
A deteriorating inventory model allowing delay in payment, promotional activities and inflation is developed. This arises as a result of the time gap in between the time of estimation and the starting time of economic order quantity (EOQ) system and promotional activities with a permissible delay in payment will affect the inventory total cost. Moreover, the political volatility of a country leads to a much more unstable situation in the present world economy. So a change in inflation takes place. The objective of this inventory model is to minimize the total inventory cost allowing promotional activities and delay in payment for deteriorating items under inflation with shortages. The numerical analysis shows that an appropriate policy can be benefited the retailer for deteriorating items. Finally, sensitivity analysis of optimal solution with respect to the major parameters are also studied.
\end{abstract}

Keywords: inventory model, deterioration, promotion, inflation, delay in payment, EOQ, shortages

Cite This Article: Bhanupriya Dash, Monalisha Pattnaik, and Hadibandhu Pattnaik, "The Impact of Promotional Activities and Inflationary Trends on a Deteriorated Inventory Model Allowing Delay in Payment." Journal of Business and Management Sciences, vol. 2, no. 3A (2014): 1-16. doi: 10.12691/jbms-2-3A-1.

\section{Introduction}

Inventory model is an important part of operations research, which may be used in variety of problems. To make it applicable in real life situation researchers are engaged in modifying existing models on different parameters under various circumstances. Inventories play a major role in the united stages economy and have been in excess of $22 \%$ of the nation's gross national product over the past few decades. As millions of dollars are tied up in inventories, proper management of these inventories can lead the organisation or company to become profitable in the entire globe. A major concern of inventory management is to know when and how much to order or manufacture so that the total cost per unit time is minimized. The total cost consists of carrying, shortage, replenishment or setup cost and the purchase or production cost. In the development of an EOQ system, we usually omit the case of inflation of money, promotional activities and deterioration of the items like fruit, milk, drug, chemicals, gasoline etc. But in the real competitive world they exist and are quite flexible in nature. On the other hand to attract customer to order more quantities, usually suppliers offer a certain credit period without interest during the permissible delay time period. Inventory management plays a significant role for production system in business since it can help companies reach the goal of ensuring prompt delivery, avoiding shortages, helping sales at competitive prices and so forth for achieving competitive advantage. However, excessive simplification of assumptions results in mathematical models that do not represent the inventory situation to be analyzed.

The classical analysis builds a model of an inventory system and calculates the EOQ which minimize the costs satisfying minimization criterion. One of the unrealistic assumption is that items stocked preserve their physical characteristics during their stay in inventory for long run. Items in stock are subject to many possible risks, e.g. damage, spoilage, dryness, vaporization etc., those results decrease of usefulness of the original one and a cost is incurred to account for such risks of the product.

The problem of deteriorating inventory has received considerable attention in recent years. This is a realistic trend since most products such as medicine, diary products and chemicals starts to deteriorate once they are produced.

Most researches in inventory do not consider inflation with promotional activities. This is unrealistic, since the resource of an enterprise depends very much on when it is used and this is highly correlated to the return of investment. Therefore, taking into account the inflation of money should be critical especially when investment and forecasting are considered. 
Buzacott (1975) [1] explained inventory model to determine economic order quantities with inflation. Datta and Pal (1991) [2] verified the effect of inflation and time value of money on an inventory model with linear time dependant demand rate and shortages. Haneveld and Teunter (1998) [3] discussed the inventory model where they studied the effects of discounting and demand rate variability on the EOQ. Holland (1995) [4] derived an inventory model where inflation and uncertainty tests for temporal ordering are allowed. Horowitz (2000) [5] presented an inventory model for obtaining EOQ under uncertain inflation of the economy. Liao et al. (2000) [6] derived an inventory model with deteriorating items under inflation when a delay in payment is permissible. Mishra (1979) [7] focused an optimal inventory management policy under inflation. Moon and Lee (2000) [8] verified the effect of inflation and time value of money on an EOQ order quantity model with random product life cycle. Pattnaik, M. (2012) [9] and Pattnaik (2014) [10] derived different types of deterministic inventory models for deteriorating items in finite horizon. Shah (1993) [11] discussed a lot size EOQ model for exponentially decaying inventory when delay in payments is permissible. Skouri and Papachristors (2002) [12] developed deterministic inventory lot-size models under inflation with shortages and deterioration for the fluctuating demand by Yang et al. Their approach was performed in the framework of the total inventory cost under inflation criterion.

The objective of this paper is to minimize the inventory cost so as to determine the optimal order quantity and promotional effort factor under inflation where shortages are allowed. The remainder of paper organized in section 2 is assumptions and notations for development of the model. The mathematical model is developed in section 3 . Optimization is given in section 4. Numerical example is presented to illustrate the development of model in section 5. The sensitivity analysis carried out in section 6 to observe the changes in optimal solution. Finally section 7 deal with conclusion.

\section{Assumption and Notation}

The mathematical model in this paper is developed with the following assumptions:

1. The replenishment is instantaneous.

2. The lead time is zero.

3. Backlogging is allowed within a small interval of time.

4. The total demand for the whole planning period is unknown and constant.

5. Discounts are not allowed and a permissible delay period will not exceed the length of a cycle.

6 . During the fixed credit period $M$, a deposit is made from the unit cost of generated sales revenue into an interest-bearing account. The delay expenses of the system can be overcome from the difference between retail price and unit cost. At the end of period $M$, the account is settled, and interest changes are payable on the account in stock.

\section{Notations}

The following notations are used

T: $\quad$ Time period of each cycle $t_{1}: \quad$ Time from where shortage begins

M: $\quad$ Permissible delay period for settling accounts

$H$ : $\quad$ Length of the planning horizon $(H=m T$, $m>1$ is a positive integer)

$I_{1}(t): \quad$ Inventory level at any time $0 \leq t \leq t_{1}$

$I_{2}(t): \quad$ Inventory level at any time $t_{1} \leq t \leq T$

Q: $\quad$ Order size per cycle

D: $\quad$ Total demand per year

$S: \quad$ Shortage quantity per cycle

$K$ : $\quad$ Rate of inflation (\$/unit time)

$\Theta$ : $\quad$ Deterioration rate $(<1)$ per unit time

$H$ : $\quad$ Holding cost per unit/year

$S_{0}$ : $\quad$ Unit shortage cost per unit time

$C(t)$ : $\quad$ Unit purchasing price for an item bought at time $\mathrm{t}$, where $\mathrm{c}(\mathrm{t})=\mathrm{c} 0(1+\mathrm{kt}), 0 \leq \mathrm{t} \leq(\mathrm{m}$ 1)t, c0 is the unit price of the item at time zero

$A(t)$ : $\quad$ Ordering cost for an order placed at time t, i.e. $\mathrm{A}(\mathrm{t})=\mathrm{A}_{0}(1+\mathrm{kt}), 0 \leq t \leq(m-1) t, A_{0}$ is unit ordering cost at time zero

$i_{e}$ : Annual interest that can be earned per

$i_{c}$ : $\quad$ Annual interest charges payable per until where $i_{c}>i_{e}$.

$P: \quad$ The promotional effort factor per cycle.

$P E(\rho)$ : The promotional effort cost, $P E=(\rho)=K_{1}(\rho-1)^{2}[d(s)]^{\alpha_{1}}$, where, $K_{1}>0$ and $\alpha_{1}$ is a constant.

\section{Mathematical Model}

The total period $H$ is divided into m equal sub-intervals of constant length $T$ such that $H-m T$. For a subinterval $(0, T)$ the inventory $Q$ is received at time $t=0$. Due to demand and deterioration, the inventory level reaches zero level at time $t=t_{1}$ and shortages start to occur. The shortage continue upto $t=T$ and accumulates to $S$ quantity. If $I_{1}(t)$ and $I_{2}(t)$ denotes the inventory lee at any time $t$ where $0 \leq t \leq t_{1}$ and $t_{1} \leq t \leq T$ respectively. Figure 1 represents the inventory level for delay in payment. Then the differential equation

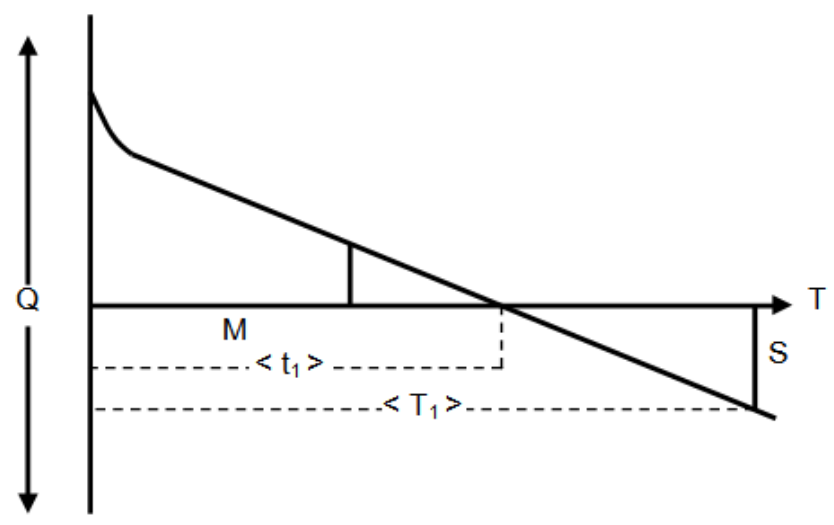

Figure 1. Inventory Level for Delay in Payment

$$
\frac{d I_{1}(t)}{d t}+\theta I_{1}(t)=-D \quad 0 \leq t_{1}
$$




$$
\frac{d I_{21}(t)}{d t}=-D \quad t_{1}<t \leq T
$$

With

$$
\mathrm{I}_{1}(0)=\mathrm{Q}-\mathrm{S}, \mathrm{I}_{1}\left(\mathrm{t}_{1}\right)=\mathrm{I}_{2}\left(\mathrm{t}_{1}\right)=0 \mathrm{I}_{2}(\mathrm{~T})=-\mathrm{S}
$$

Solving equation(1) and (2)

Equation (1) is linear differential equation.

Now Integrating factor $e^{\int \theta d t}=e^{\theta t}$

Multiplying both side of equation (1) by Integrating factor we get

$$
\begin{aligned}
& \frac{d}{d t} I_{1}(t) e^{\theta t}=-D e^{\theta t} \\
& \Rightarrow I_{1}(t) e^{\theta t}=\int D e^{\theta t} d t=-\frac{D e^{\theta t}}{\theta}+C \\
& \Rightarrow I_{1}(t)=-\frac{D}{\theta}+C e^{-\theta t}
\end{aligned}
$$

By using initial condition $\mathrm{I}_{1}\left(\mathrm{t}_{1}\right)=0$

From equation (4) $0=\frac{-D}{Q}+C e^{-\theta t t_{1}}$

$$
\begin{aligned}
& \Rightarrow C e^{-\theta t t_{1}}=\frac{D}{Q} \\
& \Rightarrow C=\frac{D e^{\theta t t_{1}}}{\theta}
\end{aligned}
$$

So

$$
\begin{aligned}
& \mathrm{I}_{1}(\mathrm{t})=\frac{-D}{\theta}+\frac{D e^{\theta \mathrm{t}_{1}}}{\theta} e^{-\theta t}=\frac{-D}{\theta}+\frac{D e^{\theta\left(t_{1}-t\right)}}{\theta} \\
& \Rightarrow I_{1}(t)=\frac{D}{\theta}\left[e^{\theta\left(t_{1}-t\right)}-1\right]
\end{aligned}
$$

From equation (2)

$$
\begin{aligned}
& \frac{D I_{2}(t)}{d t}=-D \\
\Rightarrow \quad & \int d I_{2}(t)=-\int D \cdot d t \\
\Rightarrow \quad & I_{2}(t)=-D t+C_{1}
\end{aligned}
$$

From initial condition $\mathrm{I}_{2}\left(\mathrm{t}_{1}\right)=0$ when $\mathrm{t}=\mathrm{t}_{1}$

$\mathrm{O}=-\mathrm{Dt}_{1}+\mathrm{C}_{1}$

$\Rightarrow \quad C_{1}=D t_{1}$

Hence the solution is,

$$
\mathrm{I}_{2}(\mathrm{t})=-\mathrm{Dt}+\mathrm{Dt}_{1}=\mathrm{D}\left(\mathrm{t}_{1}-\mathrm{t}\right)
$$

Shown in appendix A

$$
I_{1}(0)=Q-S \approx D\left(t_{1}+\frac{\theta t_{1}^{2}}{2}\right)
$$

and

$$
t_{1} \approx \frac{Q-S}{D}-\frac{\theta(Q-S)^{2}}{2 D^{2}}=T-\frac{S}{D}
$$

(as $\theta \leq 1$ neglecting $0\left(\theta^{2}\right)$ and higher order)

\section{Case-1: $\quad \mathbf{M}<\mathbf{t}_{1}$}

As $A(t)=$ replenishment cost at time $t$

$\mathrm{C}(\mathrm{t})=$ Purchasing cost at time $\mathrm{t}$

$\mathrm{C}_{\mathrm{r}}=$ Replenishment cost in $(\mathrm{O}, \mathrm{H})$

$C_{r}=\sum_{n=0}^{m-1} A(n T)$ Given that

$0 \leq t \leq(m-1) T, A(t)=A_{0}(1+k t)$

$C_{r}=\sum_{n=0}^{m-1} A_{0}(1+k n T)=A_{0} \sum_{n=0}^{m-1}(1+K n T)$

$=A_{0}\left[\sum_{n=0}^{m-1} 1+\sum_{n=0}^{m-1} K n T\right]$

$\therefore \quad=A_{0}\left[\begin{array}{l}\left(\begin{array}{l}0+1+1+\ldots \ldots . . \\ \text { upto } m-1\end{array}\right) \\ +K T(0+1+2+\ldots \ldots+(m-1))\end{array}\right]$

(9)

$$
\begin{aligned}
& =A_{0}\left[m+K T \frac{(m-1)(m)}{2}\right] \\
& =A_{0} m\left[1+\frac{K T}{2}(m-1)\right]
\end{aligned}
$$

The purchasing cost $\mathrm{C}_{\mathrm{p}}$ in $(\mathrm{O}, \mathrm{H})$ is

$$
\mathrm{C}_{\mathrm{p}}=Q \sum_{n=0}^{m-1} C(n T)
$$

Given $\mathrm{C}(\mathrm{t})=\mathrm{C}_{0}(1+\mathrm{Kt})$ where $0<\mathrm{t}<(\mathrm{m}-1) \mathrm{T}$

$$
\begin{gathered}
\therefore \mathrm{C}_{\mathrm{p}}=Q \sum_{n=0}^{m-1} C_{0}(1+K n T)=Q C_{0} \sum_{n=0}^{m-1}(1+K n T) \\
\therefore \mathrm{QC}_{0}\left[\sum_{n=0}^{m-1} 1+\sum_{n=0}^{m-1} K n T\right] \\
\mathrm{QC}_{0}\left[m+K T \cdot \frac{(m)(m-1)}{2}\right]=m Q C_{0}\left[1+\frac{k T(m-1)}{2}\right] \\
\therefore \quad C_{p}=m C_{0} Q\left[1+\frac{k T}{2}(m-1)\right]
\end{gathered}
$$

The holding cost in $(\mathrm{O}, \mathrm{H})$

$$
\begin{aligned}
& \mathrm{C}_{\mathrm{h}}=h \sum_{n=0}^{m-1} C(n T) \int_{0}^{t_{1}} I_{1}(t) d t \\
& =\frac{m C_{0} h(Q-S)^{2}}{2 D}\left(1-\frac{2 \theta(Q-S)}{3 D}\right)\left[1+\frac{K T}{2}(m-1)\right]
\end{aligned}
$$

The shortage cost in $(\mathrm{O}, \mathrm{H})$ is

$$
\mathrm{C}_{\mathrm{s}}=S_{0} \sum_{n=0}^{m-1} C\left(n T+t_{1}\right) \int_{t_{1}}^{T} I_{2}(t) d t
$$

But given $\mathrm{C}(\mathrm{t})=\mathrm{C}_{0}(1+\mathrm{kt})$

$$
0 \leq t \leq(m-1) T
$$

$$
\begin{aligned}
& =S_{0} \sum_{n=0}^{m-1} C\left(n T+t_{1}\right) \int_{t_{1}}^{T} D\left(t_{1}-t\right) d t \\
& =S_{0} \sum_{n=0}^{m-1} C\left(n T+t_{1}\right) \int_{t_{1}}^{T}\left(D t_{1}-D t\right) d t
\end{aligned}
$$




$$
\begin{aligned}
& =S_{0} \sum_{n=0}^{m-1} C\left(n T+t_{1}\right)\left[D t_{1} t-\frac{D t^{2}}{2}\right]_{t_{1}}^{T} \\
& =S_{0} \sum_{n=0}^{m-1} C\left(n T+t_{1}\right)\left(D t_{1} T-D t_{1}^{2}-\frac{D T^{2}}{2}+\frac{D t_{1}^{2}}{2}\right) \\
& =S_{0} \sum_{n=0}^{m-1} C\left(n T+t_{1}\right)\left(D t_{1} T-\frac{D t_{1}^{2}}{2}-\frac{D T^{2}}{2}\right) \\
& =S_{0} \sum_{n=0}^{m-1} C\left(n T+t_{1}\right) \cdot D\left(t_{1} T-\frac{t_{1}^{2}}{2}-\frac{T^{2}}{2}\right) \\
& =D\left(t_{1} T-\frac{t_{1}^{2}}{2}-\frac{T^{2}}{2}\right) S_{0} \sum_{n=0}^{m-1} C_{0}\left(1+k\left(n T+t_{1}\right)\right) \\
& =D\left(t_{1} T-\frac{T^{2}}{2}-\frac{t_{1}^{2}}{2}\right) S_{0} C_{0} \sum_{n=0}^{m-1} C_{0}\left(1+k n T+k t_{1}\right) \\
& =\frac{-m D C_{0} S_{0}}{2}\left(\frac{S}{D}\right)^{2}\left(1+k t_{1}+\frac{K T(m-1)}{2}\right) \\
& \left.=\frac{-m D C_{0} S_{0}}{2}\left(t_{1}-T\right)_{1}^{2}-\frac{T^{2}}{2}-\frac{t_{1}^{2}}{2}\right) S_{0} C_{0}\left(m+\frac{K T(m)(m-1)}{2}+k t_{1} m\right) \\
& \quad \therefore C_{0} S_{0}\left(2 T t_{1}-T^{2}-t_{1}^{2}\right)\left(1+\frac{K T(m-1)}{2}+k t_{1}\right)
\end{aligned}
$$

The interest charged for the inventory not being after the due date $\mathrm{M}$ in $(0, \mathrm{H})$ is

$$
\begin{aligned}
C_{i}= & i_{C} \sum_{n=0}^{m-1} C(n T) \int_{M}^{t_{1}} I_{1}(t) d t \\
= & \frac{i_{e} m C_{0}}{2}(Q-S-M D)\left[\left\{\begin{array}{l}
\frac{Q-S-M D}{D}-Q \\
\frac{2(Q-S)(Q-S+M D)}{3 D^{2}} \\
-\frac{M^{2}}{3}
\end{array}\right\}\right] \\
& \left\{1+\frac{K T}{2}(m-1)\right\}
\end{aligned}
$$

Detail calculation of $C_{h}$ and $C_{i}$ are given in appendix $A$. Interest earned in $(\mathrm{O}, \mathrm{H})$ is

$$
\begin{aligned}
& C_{e_{1}}=i_{e} \sum_{n=0}^{m-1} C(n T) \int_{0}^{M} D d t \\
& =i_{e} \sum_{n=0}^{m-1} C(n T) \int_{0}^{M} D[t]=i_{e} \sum_{n=0}^{m-1} C(n T) D M \\
& =i_{e} D M \sum_{n=0}^{m-1} C_{0}(1+K n T)=i_{e} D M C_{0}\left[m+\frac{K T(m)(m-1)}{2}\right]
\end{aligned}
$$

$$
C_{e_{1}}=i_{e} m M D C_{0}\left[1+\frac{K T(m-1)}{2}\right]
$$

From equation (9) - (14) the total system cost over $(0, \mathrm{H})$ is given by

$$
\begin{aligned}
& \mathrm{TC}_{1}(\mathrm{Q}, \mathrm{T})=\mathrm{C}_{\mathrm{r}}+\mathrm{C}_{\mathrm{p}}+\mathrm{C}_{\mathrm{h}}+\mathrm{C}_{\mathrm{s}}+\mathrm{C}_{\mathrm{pe}}+\mathrm{C}_{\mathrm{i}}-\mathrm{C}_{\mathrm{ei}} \\
& =\mathrm{m}\left[\mathrm{F}_{11}(\mathrm{Q}, \mathrm{S})-\mathrm{QF}_{12}(\mathrm{Q}, \mathrm{S})+\mathrm{KF}_{13}\left(\mathrm{Q}, \mathrm{S}-\mathrm{QK} \mathrm{F}_{14}(\mathrm{Q}, \mathrm{S})\right]\right. \\
& T C_{1}(Q, T)=A_{0} m\left[1+\frac{K T}{2}(m-1)\right] \\
& +m C_{0} Q\left[1+\frac{K T}{2}(m-1)\right] \\
& +\frac{m C_{0} h(Q-S)^{2}}{2 D}\left(1-\frac{2 \theta(Q-S)}{3 D}\right) \\
& \left(1+\frac{K T}{2}(m-1)\right)+\frac{m C_{0} S_{0} S^{2}}{2 D}\left(1+K t_{1}+\frac{k T}{2}(m-1)\right) \\
& +k_{1}(\rho-1)^{2} r^{\alpha_{1}}+K_{1}(\rho-1)^{2} d(s)^{\alpha_{1}} \\
& +\frac{i_{c} m C_{0}}{2}(Q-S-M D) \\
& {\left[\frac{Q-S-M D}{D}-\theta \times\left\{\frac{2 \times(Q-S)(Q-S-M D)}{3 D^{2}}-\frac{M^{2}}{3}\right\}\right]} \\
& \left\{1+\frac{K T}{2}(m-1)\right\}-\left[i_{e} m M D C_{0}\left(1+\frac{K T}{2}(m-1)\right)\right] \\
& =m A_{0}\left[1+\frac{K T}{2}(m-1)\right]+m C_{0} Q\left[1+\frac{K T}{2}(m-1)\right] \\
& +\frac{m C_{0} h(Q-S)^{2}}{2 D}\left(1+\frac{K T}{2}(m-1)\right)-\frac{m \operatorname{Coh}(Q-S)^{3} \theta}{3 D^{2}}
\end{aligned}
$$$$
\left(1+\frac{k T}{2}(m-1)\right)+\frac{m C_{0} S_{0} S^{2}}{2 D} K t_{1}+\frac{m C_{0} S_{0} S^{2}}{2 D}
$$$$
\left(1+\frac{K T}{2}(m-1)\right)+K_{1}(\rho-1)^{2} d(s)^{\alpha_{1}}
$$$$
+\frac{i_{C} m C_{0}}{2 D}(Q-S-M D)^{2}\left(1+\frac{K T}{2}(m-1)\right)
$$$$
-\frac{i_{e} M C_{0}}{2} \theta(Q-S-M D)\left\{2 \frac{(Q-S)(Q-S+M D)}{3 D^{2}}-\frac{M^{2}}{3}\right\}
$$$$
\left\{1+\frac{K T}{2}(m-1)\right\}-i_{e} m M D C_{0}\left(1+\frac{K T}{2}(m-1)\right)
$$$$
=m A_{0}+m C_{0} Q+\frac{m C_{0} h(Q-S)^{2}}{2 D}-\frac{m \operatorname{Coh}(Q-S)^{3}}{3 D^{2}} \theta
$$$$
+\frac{m C_{0} S_{0} S^{2}}{2 D}-\frac{i_{c} m C_{0}}{2 D}(Q-S-M D)^{2}-i_{e} m M D C_{0}
$$$$
-\frac{i_{e} m \theta M C_{0}}{6}\left(\begin{array}{c}
Q-S \\
-M D
\end{array}\right)\left\{2 \frac{(Q-S)(Q-S+M D)}{D^{2}}-M^{2}\right\}
$$$$
+K_{1}(\rho-1)^{2} d(s)^{\alpha_{1}}+m A_{0} \frac{K T}{2}(m-1)+m C_{0} Q \frac{k T}{2}(m-1)
$$$$
+\frac{m C_{0} h(Q-S)^{2}}{2 D} \frac{K T}{2}(m-1)
$$ 
$-\frac{m \operatorname{Coh}(Q-S)^{3} \theta}{3 D^{2}} \frac{k T}{2}(m-1) \theta$

$+\frac{m_{0} C_{0} S_{0} S^{2}}{2 D} \frac{k T}{2}(m-1)+\frac{i_{c} m C_{0}}{2 D}\left(\begin{array}{c}Q-S \\ -M D\end{array}\right)^{2} \frac{k T}{2}(m-1)$

$-\frac{i_{e} m \theta M C_{0}}{6}(Q-S-M D)$

$\left\{2 \frac{(Q-S)(Q-S+M D)}{D^{2}}-M^{2}\right\} \frac{k T}{2}(m-1)$

$-i_{e} m M D C_{0} \frac{k T}{2}(m-1)+\frac{m_{0} C_{0} S_{0} S^{2}}{2 D^{2}} k(T D-S)$

$\Rightarrow T C_{1}=m\left[\begin{array}{l}A_{0}+C_{0}\left\{\begin{array}{l}Q+\frac{h(Q-S)^{2}}{2 D}+ \\ -i_{e} M D\end{array}\right] S_{0} S^{2}+\frac{i_{c}(Q-S-M D)^{2}}{2 D}\end{array}\right\}$

$-m \theta C_{0}\left[\begin{array}{l}\frac{h(Q-S)^{3}}{3 D^{2}}+\frac{i_{c}(Q-S-M D)}{6} \\ \left(2 \frac{(Q-S)(Q-S-M D)^{2}}{D^{2}}-M^{2}\right)\end{array}\right]+\frac{m k T}{2}(m-1)$

$\left[\begin{array}{c}A_{0}+C_{0}\left(\begin{array}{l}Q+\frac{h(Q-S)^{2}}{2 D}+\frac{S_{0} S^{2}}{2 D} \\ +\frac{i_{c}(Q-S-M D)^{2}}{2 D} \\ -i_{e} M D\end{array}\right)+\frac{C_{0} S_{0} S^{2}(T(D-S)}{T D^{2}(m-1)} \\ \Rightarrow C e_{2}=m M C_{0} D i_{e}\left[1+\frac{K T}{2}(m-1)\right] \quad \therefore t_{1}=M\end{array}\right]$

$-\frac{m \theta k C_{0} T}{2}(m-1)\left[\begin{array}{l}\frac{h(Q-s)^{3}}{3 D^{2}}+\frac{i_{c}(Q-S-M D)}{6} \\ \left(2 \frac{(Q-S)(Q-S-M D)}{D^{2}}-M^{2}\right)\end{array}\right]$

$$
\therefore T C_{1}(Q, T)=m\left[\begin{array}{l}
F_{11}(Q, S)-\theta F_{12}(Q, S) \\
+K F_{13}(Q, S)-\theta K F_{14}(Q, S)
\end{array}\right]
$$

Where

$$
\begin{aligned}
& F_{11}(Q, S)=A_{0}+C_{0}\left\{\begin{array}{l}
Q+\frac{h(Q-S)^{2}}{2 D} \\
+\frac{S_{0} S^{2}}{2 D}+\frac{i_{c}(Q-S-M D)^{2}}{2 D}-i_{e} M D
\end{array}\right\} \\
& F_{12}(Q, S)=C_{0}\left[\begin{array}{l}
\frac{h(Q-S)^{3}}{3 D^{2}}+\frac{i_{C}(Q-S-M D)}{6} \\
\left(2 \frac{(Q-S)(Q-S+M D)^{2}}{D^{2}}-M^{2}\right.
\end{array}\right]
\end{aligned}
$$

$$
\begin{gathered}
F_{13}(Q, S)=\frac{(m-1) T}{2}\left[\frac{C_{0} S_{0} S^{2}(T(D-S)}{T D^{2}(m-1)}+F_{11}(Q, S)\right] \\
F_{14}(Q, S)=\frac{(m-1) T F_{12}(Q, S)}{2}
\end{gathered}
$$

Case $-\mathrm{II}\left(\mathrm{M}=\mathrm{t}_{1}\right)$

Thus using equation 9-12 and 16 we have the total system cost over $(0, \mathrm{H})$

$$
\begin{aligned}
& T C_{2}(Q, T)=C_{r}+C_{p}+C_{h}+C_{s}+C_{p e}-C e_{2} \\
& =m A_{0}\left[1+\frac{K T}{2}(m-1)\right]+m C_{0} Q\left[1+\frac{K T}{2}(m-1)\right] \\
& +\frac{m C_{0} h(Q-S)^{2}}{2 D}\left(1-\frac{2 \theta(Q-S)}{3 D}\right)\left[1+\frac{k T}{2}(m-1)\right] \\
& +\frac{m C_{0} S_{0} S^{2}}{2 D}\left[1+k t_{1}+\frac{K T}{2}(m-1)\right] \\
& -i_{e} m M D C_{0}\left\{1+\frac{K T}{2}(m-1)\right\}+K_{1}(\rho-1)^{2} d(s)^{\alpha_{1}} \\
& =m A_{0}+m C_{0} Q+\frac{m C_{0} h(Q-S)^{2}}{2 D}\left[1+\frac{K T}{2}(m-1)\right] \\
& +\frac{m C_{0} S_{0} S^{2}}{2 D}\left[1+\frac{K T}{2}(m-1)\right]-i_{e} C_{0} m M D \\
& -\frac{m C_{0} \theta h(Q-S)^{3}}{3 D^{2}}\left[1+\frac{k T}{2}(m-1)\right]+\frac{m C_{0} S_{0} S^{2}}{2 D} k t_{1} \\
& -i_{e} m M D C_{0} \frac{K T}{2}(m-1)+m A_{0} \frac{K T}{2}(m-1) \\
& +m C_{0} Q \frac{K T(m-1)}{2}+K_{1}(\rho-1)^{2} d(s)^{\alpha_{1}} \\
& =m A_{0}+m C_{0} Q+\frac{m C_{0} h(Q-S)^{2}}{2 D}+\frac{m C_{0} S_{0} S^{2}}{2 D} \\
& -i_{e} C_{0} m M D-\frac{m C_{0} \theta h(Q-S)^{3}}{3 D^{2}}+\frac{m C_{0} S_{0} S^{2}}{2 D^{2}} K M \\
& +\frac{m C_{0} h(Q-S)^{2}}{2 D} \frac{K T(m-1)}{2}+\frac{m C_{0} S_{0} S^{2}}{2 D} \frac{K T}{2}(m-1) \\
& -\frac{m C_{0} \theta h(Q-S)^{3}}{3 D^{2}} \frac{K T}{2}(m-1)-i_{e} m M D C_{0} \frac{K T}{2}(m-1) \\
& +m A_{0} \frac{K T}{2}(m-1)+m C_{0} Q \frac{K T}{2}(m-1)+K_{1}(\rho-1)^{2} d(s)^{\alpha_{1}} \\
& -m A_{0}+m C_{0} Q+\frac{m C_{0} h(Q-S)^{2}}{2 D}+\frac{m C_{0} S_{0} S^{2}}{2 D}-i_{e} C_{0} m M D \\
& -\frac{m C_{0} h(Q-S)^{3}}{3 D^{2}} \theta+\frac{m C_{0} S_{0} S^{2}}{2 D} M+\frac{m C_{0} h(Q-S)^{2}}{2 D} \\
& \times \frac{T}{2}(m-1)+\frac{m C_{0} S_{0} S^{2}}{4 D} T(m-1)-i_{e} m M D C_{0} \frac{T}{2}(m-1) \\
& +m A_{0} \frac{T}{2}(m-1)+m C_{0} Q \frac{T}{2}(m-1) k- \\
& {\left[\frac{m C_{0} h(Q-S)^{3} T(m-1)}{6 D^{2}} \times \theta k\right]}
\end{aligned}
$$




$$
\begin{aligned}
& =m\left[\left(\begin{array}{l}
A_{0}+C_{0} Q+\frac{C_{0} h(Q-S)^{2}}{2 D} \\
+\frac{C_{0} S_{0} S^{2}}{2 D}-i_{e} C_{0} D
\end{array}\right)\right] \\
& +\frac{m C_{0} S_{0} S^{2} T(m-1)}{4 D}-\frac{i_{e} M D C_{0} T(m-1)}{2}+\frac{A_{0} T(m-1)}{2} \\
& \left.+\frac{m C_{0} Q T(m-1)}{2}\right\} K-\left(\frac{C_{0} h(Q-S)^{3} T(m-1)}{6 D^{2}}\right) \theta K
\end{aligned}
$$$$
+K_{1}(\rho-1)^{2} d(s)^{\alpha_{1}}
$$$$
=m\left[\begin{array}{l}
\left(\begin{array}{l}
A_{0}+C_{0}\left(Q+\frac{h(Q-S)}{2 D}\right. \\
+\frac{S_{0} S^{2}}{2 D}-i_{e} M D
\end{array}\right)-\left(\frac{C_{0} h(Q-S)^{3}}{3 D^{2}}\right) \theta \\
+\left[\frac{(m-1) T}{2}\right]\left(\frac{C_{0} S_{0} S^{2} M}{D(m-1) T}+C_{0} Q\right. \\
\left.\left.+A_{0}+\frac{C_{0} S_{0} S^{2}}{2 D}-i_{e} M D C_{0}+\frac{C_{0} h(Q-S)^{2}}{2 D}\right)\right] k \\
-\left(\frac{C_{0} h(Q-S)^{3}}{3 D^{2}} \theta k \frac{(m-1) T}{2}\right)
\end{array}\right]
$$$$
\left[\left\{A_{0}+C_{0} Q+\frac{h(Q-S)^{2}}{2 D}+\frac{S_{0} S^{2}}{2 D}-i_{e} M D\right\}\right.
$$$$
+\left(\frac{C_{0} h(Q-S)^{3}}{3 D^{2}}\right) \theta+
$$

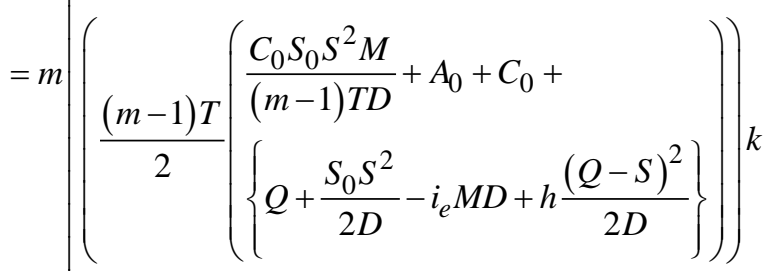$$
+\left(\frac{(m-1) T}{2}\left(\frac{C_{0} h(Q-S)^{3}}{3 D^{2}}\right)\right) \theta K
$$$$
+K_{1}(\rho-1)^{2} d(s)^{\alpha_{1}}
$$$$
\therefore T C_{2}(Q, T)=m\left[\begin{array}{l}
F_{21}(Q, S)-\theta F_{22}(Q, S) \\
+K F_{23}(Q, S)-\theta K F_{24}(Q, S)
\end{array}\right]
$$$$
+K_{1}(\rho-1)^{2} d(s)^{\alpha_{1}}
$$

Where

$$
\begin{array}{r}
F_{21}(Q, S)=\left[A_{0}+C_{0}\left\{Q+\frac{h(Q-S)^{2}}{2 D}+\frac{S_{0} S^{2}}{2 D}-i_{e} M D\right\}\right] \\
F_{22}(Q, S)=\frac{C_{0} h(Q-S)^{3}}{3 D^{2}} \\
F_{23}(Q, S)=\frac{(m-1) T}{2}\left[\frac{C_{0} S_{0} S^{2} M}{(m-1) T D}+F_{21}(Q, S)\right]
\end{array}
$$

$$
F_{24}(Q, S)=\frac{(m-1) T F_{22}(Q, S)}{2}
$$

Case-III $t_{1}<M<T$

No interest is charged in $(0, \mathrm{H})$ because the supplier can be paid in full at the time of permissible delay and hence the interest earned in $(0, \mathrm{H})$ is

$$
\begin{aligned}
& C_{e_{3}}=i_{e} \sum_{n=0}^{m-1} C(n T) \cdot \int_{0}^{t_{1}} D d t+\left(M-t_{1}\right) D t_{1} \\
& =i_{e} \sum_{n=0}^{m-1} C(n T) \cdot\left\{D d t+\left(M-t_{1}\right) D t_{1}\right\} \\
& \left.=i_{e} \sum_{n=0}^{m-1} C(n T) \cdot\left\{\begin{array}{l}
D\left(\frac{(D T-S)}{D}\right)+ \\
\left(M-\frac{(D T-S)}{D}\right) D\left(\frac{(D T-S)}{D}\right)
\end{array}\right)\right\} \\
& =i_{e} \sum_{n=0}^{m-1} C(n T) \cdot\left\{(D T-S)+\left(\frac{(M D-D T+S)}{D}\right)(D T-S)\right\} \\
& =i_{e} \sum_{n=0}^{m-1} C(n T) \cdot\left\{(D T-S)\left(1+\frac{(M D-D T+S)}{D}\right)\right\} \\
& =i_{e} \sum_{n=0}^{m-1} C(n T) \cdot\left\{\frac{(D T-S)(D+M D-D T+S)}{D}\right\} \\
& =i_{e} \frac{(T D-S)(D+S+M D-D T)}{D} \sum_{n=0}^{m-1} C_{0}(1+k n T) \\
& =i_{e} \frac{(T D-S)\left(\begin{array}{l}
D+S \\
+M D-D T
\end{array}\right)}{D} C_{0}\left\{m+\frac{k T m(m-1)}{2}\right\} \\
& =\frac{i_{e} m C_{0}(T D-S)\left(\begin{array}{l}
D+S \\
+M D-D T
\end{array}\right)\left(1+\frac{k T}{2}(m-1)\right.}{D},
\end{aligned}
$$

Using $C_{r}, C_{\rho}, C_{h}^{\prime}, C_{S}$ and $C_{\rho_{e}}$ and $C_{e_{3}}$

The total system cost over $(0, \mathrm{H})$

$$
\begin{aligned}
& \mathrm{TC}_{3}(\mathrm{Q}, \mathrm{T})=\mathrm{C}_{\mathrm{r}}+\mathrm{C}_{\mathrm{p}}+\mathrm{C}_{\mathrm{h}}+\mathrm{C}_{\mathrm{s}}+\mathrm{C}_{\mathrm{pe}}-\mathrm{Ce}_{3} \\
& =m A_{0}\left[1+\frac{K T}{2}(m-1)\right]+m C_{0} Q\left[1+\frac{K T}{2}(m-1)\right] \\
& +\frac{m C_{0} h(Q-S)^{2}}{2 D}\left(1-\frac{2 Q(Q-S)}{3 D}\right)\left[1+\frac{K T}{2}(m-1)\right] \\
& +\frac{m C_{0} S_{0} S^{2}}{2 D}\left[1+k t_{1}+\frac{K T}{2}(m-1)\right]+K_{1}(\rho-1)^{2} d(s)^{\alpha_{1}} \\
& -\frac{i_{e} m C_{0}(T D-S)(D+S+M D-T D)}{D}\left\{1+\frac{K T}{2}(m-1)\right\} \\
& =m A_{0}+m C_{0} Q+\frac{m C_{0} h(Q-S)^{2}}{2 D}\left(1-\frac{2 Q(Q-S)}{3 D}\right) \\
& +\frac{m C_{0} S_{0} S^{2}}{2 D}-i_{e} m C_{0}(T D-S)\left(\frac{D+S+M D-T D}{D}\right) \\
& +m A_{0} \frac{K T}{2}(m-1)+m C_{0} Q \frac{K T}{2}(m-1)
\end{aligned}
$$




$$
\begin{aligned}
& +\frac{m C_{0} h(Q-S)^{2}}{2 D}\left(1-\frac{2 \theta(Q-S)}{3 D}\right) \frac{K T}{2}(m-1) \\
& +\frac{m C_{0} S_{0} S^{2}}{2 D}\left[K t_{1}+\frac{K T}{2}(m-1)\right]+K_{1}(\rho-1)^{2} d(s)^{\alpha_{1}} \\
& =m A_{0}+m C_{0} Q+\frac{m C_{0} h(Q-S)^{2}}{2 D}+\frac{m C_{0} S_{0} S^{2}}{2 D} \\
& -i_{e} \frac{m C_{0}(T D-S)(D+S+M D-T D)}{D} \\
& -\frac{m C_{0} h(Q-S)^{2}}{2 D} \times 2 \theta \frac{(Q-S)}{3 D} \\
& +m A_{0} \frac{K T}{2}(m-1)+m C_{0} Q \frac{K T}{2}(m-1)+ \\
& \frac{m C_{0} h(Q-S)^{2}}{2 D} \times \frac{K T}{2}(m-1) \\
& +\frac{m C_{0} S_{0} S^{2}}{2 D}\left[K \cdot \frac{T D-S}{D}+\frac{K T}{2}(m-1)\right]-i_{e} m C_{0} \times \\
& \frac{(T D-S)(D+S+M D-T D)}{D} \times \frac{K T}{2}(m-1) \\
& -\frac{m C_{0} h(Q-S)^{2}}{2 D} \times \frac{2 \theta(Q-S)}{3 D} \times \frac{K T}{2}(m-1) \\
& +K_{1}(\rho-1)^{2} d(s)^{\alpha_{1}}
\end{aligned}
$$

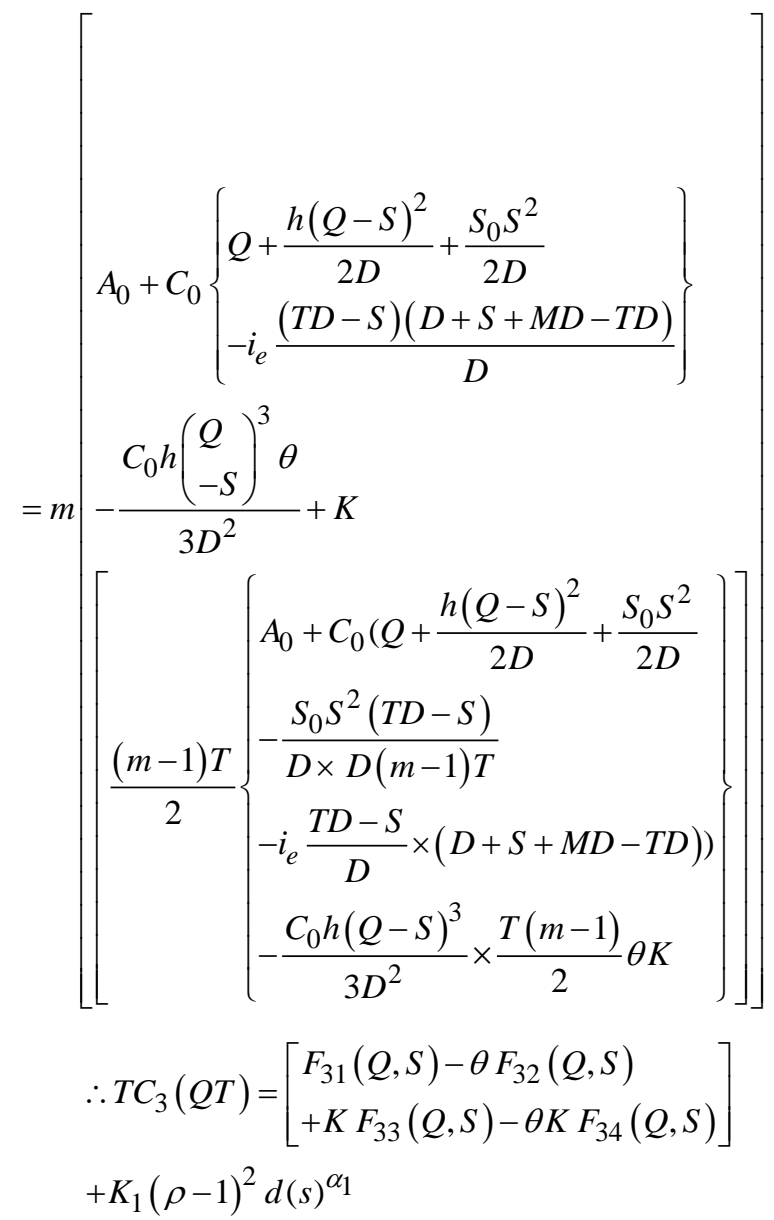

$$
\begin{aligned}
& \text { Where } F_{31}=\left[A_{0}+C_{0}\left\{\begin{array}{l}
Q+\frac{h(Q-S)^{2}}{2 D}+\frac{S_{0} S^{2}}{2 D} \\
-i_{e}(T D-S) \\
\times \frac{(D+S+M D-T D)}{D}
\end{array}\right\}\right] \\
& F_{32}(Q, S)=\frac{C_{0} h(Q-S)^{3}}{3 D^{2}}
\end{aligned}
$$$$
F_{33}(Q, S)=\frac{(m-1) T}{2}\left\{+C_{0}\left(\begin{array}{l}
A_{0} \\
+\frac{h(Q-S)^{2}}{2 D} \\
+\frac{S_{0} S^{2}}{2 D}+\frac{S_{0} S^{2}(T D-S)}{D^{2}(m-1) T} \\
-i_{e} \frac{T D-S}{D}\left(\begin{array}{l}
D+S \\
+M D-T D
\end{array}\right)
\end{array}\right)\right\}
$$$$
=\frac{(m-1) T}{2}\left\{\begin{array}{l}
\frac{C_{0} S_{0} S^{2}(T D-S)}{D^{2}(m-1) T} \\
+F_{31}(Q, S)
\end{array}\right\}
$$$$
\& F_{34}(Q, S)=\frac{(m-1) T C_{0} h(Q-S)^{3}}{2 \times 3 \times D^{2}}
$$$$
=\frac{T(m-1) F_{32}(Q, S)}{2}
$$$$
C_{p e}=K_{1}(\rho-1)^{2} d(S)^{\alpha_{1}}
$$

\section{Solution Procedure}

Choosing two initial values of $\mathrm{m}^{*}$ say $\mathrm{m}$ and $(\mathrm{m}-1)$ in $\mathrm{Z}(\mathrm{m})$. Compute $\mathrm{T}^{*}=\mathrm{Hm}^{*}$ and then optimize $\mathrm{Z}(\mathrm{m})$ and $\mathrm{Z}(\mathrm{m}-1)$ with the help of LINGO software to find the parameters $Q^{*}, \mathrm{~S}^{*}, \mathrm{t}_{1}{ }^{*}$ in each case.

Step-1:

If $\mathrm{Z}^{*}(\mathrm{~m}) \geq Z_{i} *(K+1)$ then set $\mathrm{m}^{*}=\mathrm{k}$ and stop.

\section{Numerical Example}

Here we have consider following numerical example. Let $\mathrm{A}_{0}=\$ 7.5, \mathrm{C}_{0}=\$ 2.5, \mathrm{M}=0.3 \mathrm{yr}$ (case 1 only) $\mathrm{I}_{\mathrm{C}}=\$ 0.11, \mathrm{i}_{\mathrm{e}}=\$ 0.09, \mathrm{D}=500$ units per year. $\mathrm{h}=\$ 0.18, \mathrm{H}=1$ year, $\mathrm{K}=0.5, \mathrm{Q}=0.004$ $\mathrm{S}_{0}=\$ 0.5, \mathrm{k}_{1}=2.00, \alpha_{1}=1.0$

For the given data the total net value profit for the planning horizon $\pi$ is Rs.74703.13, the number of replenishment during planning horizon $N$, is 26 , per unit selling price of the items is Rs. 18.52, time with positive inventory $T_{1}$, is 0.2649512 , replenishment cycle $T$ is 0.3856304 , selling price dependent declining quadratic demand $d(s)$ is 570.3798 and the replenishment size $Q$ is 220.0833. The total number of order is therefore $N+1=27$. All the decision parameters are compared with the other model related to the declined demand $d(S)$ which is also related linearly to the selling price. It is observed that demand rate $d(s)$, order quantity $Q$, time with positive 
inventory $T_{1}$ and replenishment cycle $T$ are more than the compared model. But only the number of replenishment during planning horizon, $N$, selling price $\mathrm{S}$, unit selling prices and the total present value profit $\pi$ are less from the compared model.

\section{Sensitivity Analysis}

It is interesting to investigate the influence of major parameters

$$
A_{0}, C_{0}, M_{1}, I_{C}, I_{e}, D, h, H, K, \theta, S_{0}, S, m, T, t_{1}, Q, \rho, P E
$$

and $T C$ by taking six cases such that $A_{1}, A_{2}, A_{3}, B_{1}, B_{2}$ and $B_{3}$ are represented in appendix- B.

Case- $A_{1}$ :

- $S, m, T, t_{1}, Q, \rho, P E$ and $T C$ are insensitive to the parameter $A_{0}$.

- $\quad S, m, T, t_{1}, Q, \rho$ and $P E$ are insensitive to the parameter $C_{0}$ but TC is moderately sensitive to $C_{0}$.

- $S, m, T, t_{1}, \rho$ and $P E$ are insensitive to $M_{1}, Q$ is moderately sensitive to $M_{1}$ but TC is highly sensitive to $M_{1}$.

- $S, m, T, t_{1}, Q, \rho, P E$ and $T C$ are insensitive to the parameter $I_{C}$.

- $\quad S, m, T, t_{1}, Q, \rho$ and $P E$ are insensitive to the parameter to $I_{e}$ but TC is moderately sensitive to $I_{e}$.

- $S, m, T, t_{1}, \rho$ and PE are insensitive to D. Q and TC are moderately sensitive to $\mathrm{D}$.

- $S, m, T, t_{1}, Q, \rho, P E$ and $T C$ are insensitive to $h$.

- $S, m, T, t_{1}, Q, \rho, P E$ and $T C$ are insensitive to parameter $\mathrm{H}$.

- $S, m, T, t_{1}, Q, \rho, P E$ and $T C$ are insensitive to parameter $\mathrm{K}$.

- $S, m, T, t_{1}, Q, \rho, P E$ and $T C$ are insensitive to parameter $\theta$.

- $\quad S, m, T, t_{1}, Q, \rho, P E$ and $T C$ are insensitive to parameter $S_{0}$.

Case- $A_{2}$ :

- $S, m, T, t_{1}, Q, \rho, P E$ and $T C$ are insensitive to the parameter $A_{0}$.

- $\mathrm{S}$ and $\mathrm{Q}$ are moderately sensitive to the parameter $C_{0}$.

- $C_{0} \cdot m, T, t_{1}, \rho, P E$ and $T C$ are insensitive to the parameter $C_{0}$.

- $T, t_{1}, \rho$ and $P E$ are insensitive to $M_{1}$. TC is moderately sensitive to $M_{1}$ but $\mathrm{S}$ and $\mathrm{Q}$ are highly sensitive to $M_{1}$.

- $S, m, T, t_{1}, Q, \rho, P E$ and $T C$ are insensitive to the parameter $I_{C}$.

- $m, T, t_{1}, \rho$ and $P E$ are insensitive to the parameter to $I_{e}$ but $\mathrm{S}$ and $\mathrm{Q}$ are highly sensitive to the parameter $I_{e}$. TC is moderately sensitive to $I_{e}$.
- $S, m, T, t_{1}, Q, \rho$ and $P E$ are insensitive to D. TC are moderately sensitive to $\mathrm{D}$.

- $m, T, t_{1}, Q, \rho$ and $P E$ are insensitive to h. S and Q are highly sensitive to $\mathrm{h}$ and $\mathrm{TC}$ is moderately sensitive to h.

- $m, T, t_{1}, \rho$ and $P E$ are insensitive to parameter $\mathrm{H}$ and $\mathrm{S}, \mathrm{Q}$ and TC are moderately sensitive to $\mathrm{H}$.

- $m, T, t_{1}, \rho$ and $P E$ are insensitive to parameter $\mathrm{K}$ but $\mathrm{S}, \mathrm{Q}$ and TC are moderately sensitive to the parameter K.

- $S, m, T, t_{1}, Q, \rho, P E$ and $T C$ are insensitive to parameter $\theta$.

- $m, T, t_{1}, \rho, P E$ and $T C$ are insensitive to parameter $S_{0}$ but $\mathrm{S}$ is highly sensitive to $S_{0}$. Q is moderately sensitive to $S_{0}$.

- $S, m, T, t_{1}, Q, \rho, P E$ and $T C$ are insensitive to the parameter $K_{1}$.

- $S, m, T, t_{1}, Q, \rho, P E$ and $T C$ are insensitive to the parameter $\alpha_{1}$.

Case- $A_{3}$

- $S, m, T, t_{1}, Q, \rho, P E$ and $T C$ are insensitive to the parameter $A_{0}$.

- $\mathrm{S}$ and TC are moderately sensitive to $C_{0} . m, T, t_{1}, Q, \rho$ and $P E$ are insensitive to the parameter $C_{0}$.

- $m, T, t_{1}, \rho$ and $P E$ are insensitive to $M_{1}$. S, Q and TC are moderately sensitive to $M_{1}$.

- $S, m, T, t_{1}, Q, \rho, P E$ and $T C$ are insensitive to the parameter $I_{C}$.

- $m, T, t_{1}, \rho$ and $P E$ are insensitive to the parameter to $I_{e}$ but $\mathrm{S}$ is highly sensitive to the parameter $I_{e}$. Q and TC is moderately sensitive to $I_{e}$.

- $S, m, T, t_{1}, \rho$ and $P E$ are insensitive to D. Q and TC are moderately sensitive to $\mathrm{D}$.

- $m, T, t_{1}, Q, \rho$ and $P E$ are insensitive to h. S, Q and T are moderately sensitive to $h$.

- $m, T, t_{1}, \rho$ and $P E$ are insensitive to parameter $\mathrm{H}$ and $\mathrm{S}, \mathrm{Q}$ and TC are moderately sensitive to $\mathrm{H}$.

- $m, T, t_{1}, \rho$ and $P E$ are insensitive to parameter $\mathrm{K}$ but $\mathrm{S}, \mathrm{Q}$ and TC are moderately sensitive to the parameter $\mathrm{K}$.

- $S, m, T, t_{1}, Q, \rho, P E$ and $T C$ are insensitive to parameter $\theta$.

- $m, T, t_{1}, \rho, P E$ and $T C$ are insensitive to parameter $S_{0}$ but $\mathrm{S}$ and $\mathrm{Q}$ is moderately sensitive to $S_{0}$.

- $S, m, T, t_{1}, Q, \rho, P E$ and $T C$ are insensitive to the parameter $K_{1}$.

- $S, m, T, t_{1}, Q, \rho, P E$ and $T C$ are insensitive to the parameter $\alpha_{1}$.

Case- $B_{1}$

- $S, m, T, t_{1}, Q, \rho, P E$ and $T C$ are insensitive to the parameter $A_{0}$. 
- $S, m, T, t_{1}, Q, \rho, P E$ and $T C$ are insensitive to the parameter $C_{0}$.

- $S, m, T, t_{1}, \rho$ and $P E$ are insensitive to $M_{1}$. Q and TC are moderately sensitive to $M_{1}$.

- $S, m, T, t_{1}, Q, \rho, P E$ and $T C$ are insensitive to the parameter $I_{C}$.

- $S, m, T, t_{1}, Q, \rho$ and $P E$ are insensitive to the parameter to $I_{e}$ but TC is moderately sensitive to $I_{e}$.

- $S, m, T, t_{1}$, and $\rho$ are insensitive to D. Q, PE and TC are moderately sensitive to $D$.

- $S, m, T, t_{1}, Q, \rho$ and $P E$ are insensitive to $h$. TC is moderately sensitive to $h$.

- $m, T, t_{1}, \rho$ and $P E$ are insensitive to parameter $\mathrm{H}$ and $\mathrm{S}, \mathrm{Q}$ and TC are moderately sensitive to $\mathrm{H}$.

- $m, T, t_{1}, \rho$ and $P E$ are insensitive to parameter $\mathrm{K}$ but $\mathrm{S}, \mathrm{Q}$ and TC are moderately sensitive to the parameter K.

- $S, m, T, t_{1}, Q, \rho, P E$ and $T C$ are insensitive to parameter $\theta$.

- $m, T, t_{1}, \rho, P E$ and TC are insensitive to parameter $S_{0}$ but $\mathrm{S}$ and $\mathrm{Q}$ is moderately sensitive to $S_{0} \ldots$

- $S, m, T, t_{1}, Q, \rho, P E$ and $T C$ are insensitive to the parameter $K_{1}$.

- $S, m, T, t_{1}, Q, \rho, P E$ and $T C$ are insensitive to the parameter $\alpha_{1}$.

Case-B2 $=$ Case-B3

- $S, m, T, t_{1}, Q, \rho, P E$ and $T C$ are insensitive to the parameter $A_{0}$.

- $\mathrm{S}$ and TC are moderately sensitive to $C_{0} . m, T, t_{1}, Q, \rho$ and $P E$ are insensitive to the parameter $C_{0}$.

- $m, T, t_{1}, \rho$ and $P E$ are insensitive to $M_{1}$. S, Q and TC are moderately sensitive to $M_{1}$.

- $S, m, T, t_{1}, Q, \rho, P E$ and $T C$ are insensitive to the parameter $I_{C}$.

- $m, T, t_{1}, \rho$ and $P E$ are insensitive to the parameter to $I_{e}$ but $\mathrm{S}$ is highly sensitive to the parameter $I_{e}$. Q and TC is moderately sensitive to $I_{e}$.

- $S, m, T, t_{1}, \rho$ and PE are insensitive to D. Q and TC are moderately sensitive to $\mathrm{D}$.

- $m, T, t_{1}, Q, \rho$ and $P E$ are insensitive to h. S, Q and T are moderately sensitive to $h$.

- $m, T, t_{1}, \rho$ and $P E$ are insensitive to parameter $\mathrm{H}$ and $\mathrm{S}, \mathrm{Q}$ and TC are moderately sensitive to $\mathrm{H}$.

- $m, T, t_{1}, \rho$ and $P E$ are insensitive to parameter $\mathrm{K}$ but

$\mathrm{S}, \mathrm{Q}$ and TC are moderately sensitive to the parameter $\mathrm{K}$.

- $\quad S, m, T, t_{1}, Q, \rho, P E$ and $T C$ are insensitive to parameter $\theta$.

- $m, T, t_{1}, \rho, P E$ and TC are insensitive to parameter $S_{0}$ but $\mathrm{S}$ and $\mathrm{Q}$ is moderately sensitive to $S_{0}$.
- $S, m, T, t_{1}, Q, \rho, P E$ and $T C$ are insensitive to the parameter $K_{1}$.

- $S, m, T, t_{1}, Q, \rho, P E$ and $T C$ are insensitive to the parameter $\alpha_{1}$.

\section{Conclusion}

In this paper, an EPQ model is introduced which investigates the optimal replenishment quantity. Unit selling price, replenishment cycle, time with positive invention the total value net profit with finite planning horizon for deteriorating items. The model considers the impact of price dependant quadratic demand, and shortages and varying rate of deterioration. The model can be used for electronics and other luxury products which are more likely to have the above characteristics. This paper provides a useful property for finding the optimal net present value profit with finite planning horizon for deteriorating items. A new mathematical model with decline quadratic demand is developed and compared to the other EPQ model with decline linear demand and numerically. The economic replenishment quantity $Q^{*}$ and net present value profit $\pi^{*}$ for the present model were found to be more than that of the compared model respectively. Hence the utilization of selling price dependent declined quadratic demand makes the scope of application broader. Lingo 13.0 version software is used to derive the optimal number of replenishment and unit price to maximize the total present value net profit. Further, a numerical example is presented to illustrate the theoretical results, and some observations are obtained from sensitivity analysis with respect to the major parameters controlling the market demand through the manipulation of selling price is an important strategy for increasing profit. This can be achieved by using the joint optimal replenishment and pricing strategy developed in this study. In the future study, it is hoped further incorporate the proposed model into several situations such as stochastic market demand, fuzzy decision parameters and partial back logging.

\section{References}

[1] Buzacott, J.A. (1975). Economic order quantities with inflation. Operations Research Quarterly, 26: 553-558.

[2] Datta, T.K. and Pal, A.K. (1991). Effect of inflation and time value of money on an inventory model with linear time dependant demand rate and shortages. European Journal Operational Research, 52: 326-333.

[3] Haneveld, W.K. and Teunter, R.H. (1998). Effects of discounting and demand rate variability on the EOQ. International Journal of Production Economics, 54: 173-192.

[4] Holland, A.S. (1995). Inflation and uncertainty tests for temporal ordering. Journal of Money Credit Bank, 27: 827-837.

[5] Horowitz, I. (2000). EOQ and inflation uncertainty. International Journal Production Economics, 65: 217-224.

[6] Liao, H.C., Tsai C.H. and Su, C.T. (2000). An inventory model with deteriorating items under inflation when a delay in payment is permissible, International Journal Production Economics, 63: 207-214.

[7] Mishra, R.B. (1979). A note an optimal inventory management under inflation, Naval Research Logistic Quarterly, 26: 161-165.

[8] Moon, I. and Lee, S. (2000). The effect of inflation and time value of money on an EOQ order quantity model with random product 
life cycle, European Journal of Operational Research, 125: 588601.

[9] Pattnaik, M. (2012). Models of Inventory Control, Lambart Academic Publishing, Germany.

[10] Pattnaik, M. (2014). Inventory Models: A Management Perspective, Lambart Academic Publishing, Germany.
[11] Shah, N.H. (1993). A lot size model for exponentially decaying inventory when delay in payments is permissible, Cahiers $d u$ CERO, 35: 115-123.

[12] Skouri, K. and Papachristors, S. (2002). Note on deterministic inventory lot-size models under inflation with shortages and deterioration for the fluctuating demand by Yang et al. Naval Research Logistics, 49: 527-529.

\section{Appendix -A}

$$
\begin{aligned}
& Q-S=I_{1}(0)=\frac{D}{\theta}\left(e^{\theta t_{1}}-1\right) \ldots \ldots \ldots \ldots . . A 1 \\
& =\frac{D}{\theta}\left[1+\theta t_{1}+\frac{\theta^{2} t_{1}^{2}}{2}+\frac{\theta^{3} t_{1}^{3}}{6}+\frac{\theta^{4} t_{1}^{4}}{24}+\ldots \ldots \ldots \ldots \ldots . . . . .1\right] \\
& =D\left[t_{1}+\frac{\theta t_{1}^{2}}{2}+\frac{\theta^{2} t_{1}^{3}}{6}+\frac{\theta^{3} t_{1}^{4}}{24}+\ldots \ldots \ldots \ldots \ldots . . .\right] \\
& =D\left[\left(t_{1}+\frac{\theta t_{1}^{2}}{2}\right)+\theta^{2}\left(\frac{t_{1}^{3}}{6}+\frac{\theta t_{1}^{4}}{24}+\ldots \ldots \ldots \ldots \ldots . . . . . .\right)\right] \\
& \approx D\left(t_{1}+\frac{\theta t_{1}^{2}}{2}\right)\left(\text { Since } \theta \leq 1 \text { So, } \theta^{2} \text { \& higher power of } \theta \text { neglected }\right)
\end{aligned}
$$

From equation $\mathrm{A}_{1}$ we have $e^{\theta t_{1}}=1+\frac{\theta(Q-S)}{D}$

$$
\begin{aligned}
& Q-S=\frac{D}{\theta}\left(e^{\theta t_{1}}-1\right) \\
& \Rightarrow \quad e \theta t_{1}-1=\frac{(Q-S) \theta}{D} \\
& \Rightarrow \quad e^{\theta t_{1}}=1+\frac{(Q-S) \theta}{D} \\
& \Rightarrow \quad \theta t_{1}=\log \left[1+\frac{(Q-S) \theta}{D}\right] \\
& t_{1}=\frac{1}{\theta} \log \left[1+\frac{(Q-S) \theta}{D}\right]=\frac{1}{\theta}\left[\frac{\theta(Q-S)}{D}-\frac{\theta^{2}(Q-S)^{2}}{2 D^{2}}+\frac{\theta^{3}(Q-S)^{3}}{3 D^{3}} \ldots \ldots . .\right]= \\
& \Rightarrow \quad\left[\frac{Q-S}{D} \cdot \frac{\theta(Q-S)^{2}}{2 D^{2}}+\frac{\theta^{2}(Q-S)^{3}}{3 D^{3}} \ldots \ldots \ldots\right]
\end{aligned}
$$

Since $\theta \leq 1$ So neglect $\theta^{2}$ .A3

$$
\begin{gathered}
t_{1}^{2}=\frac{(Q-S)^{2}}{D^{2}}-\frac{\theta(Q-S)^{3}}{D^{3}} \\
t_{1}^{3}=\left[\frac{Q-S}{D}-\frac{\theta(Q-S)^{2}}{2 D^{2}}\right]^{3} \\
=\left(\frac{Q-S}{D}\right)^{3}-\frac{\theta^{3}(Q-S)^{6}}{8 D^{6}}-3 \frac{(Q-S)^{2}}{D^{2}} \frac{\theta(Q-S)^{2}}{2 D^{2}}+3\left(\frac{Q-S}{D}\right) \cdot \frac{\theta^{2}(Q-S)^{4}}{4 D^{4}} \\
\Rightarrow \frac{\theta t_{1}^{3}}{6}=\frac{\theta(Q-S)^{3}}{6 D^{3}}-\frac{\theta^{4}(Q-S)^{6}}{48 D^{6}}-\frac{3 \theta^{2}(Q-S)^{2}}{12 D^{4}}+3 \frac{\theta^{3}(Q-S)^{5}}{24 D^{5}} \\
=\frac{\theta(Q-S)^{3}}{6 D^{3}}-\frac{\theta^{4}(Q-S)^{6}}{48 D^{6}}-\frac{\theta^{2}(Q-S)^{4}}{4 D^{4}}+\frac{\theta^{3}(Q-S)^{6}}{8 D^{5}} \\
\frac{\theta t_{1}^{3}}{6} \approx \frac{\theta(Q-S)^{3}}{Q D^{3}} \text { as } \theta \leq 1 \text { neglecting higher power of } \theta
\end{gathered}
$$


The holding cost $(\mathrm{O}, \mathrm{H})$

$$
\begin{aligned}
& C_{h}=h \sum_{n=0}^{n-1} C(n T) \int_{0}^{t_{1}} I_{1}(t) d t=h \sum_{n=0}^{n-1} C(n t) \int_{0}^{t_{1}} \frac{D}{\theta}\left(e^{\theta\left(t_{1}-t\right)}-1\right) d t \\
& =h \sum_{n=0}^{m-1} C(n T)\left\{\frac{D}{\theta} \int_{0}^{t_{1}}\left(e^{\theta t_{1}} \cdot e^{-\theta t}-1\right) d t\right\} \\
& =h \sum_{n=0}^{m-1} C(n T)\left\{\frac{D}{\theta}\left[\frac{e^{\theta t_{1}} e^{-\theta t}}{\theta}-t\right]_{0}^{t_{1}}\right\} \\
& =h \sum_{n=0}^{m-1} C(n T)\left\{\frac{D}{\theta^{2}}\left[-e^{\theta\left(t_{1}-t\right)}-t \theta\right]_{0}^{t_{1}}\right\} \\
& =h \sum_{n=0}^{m-1} C(n T)\left\{\frac{D}{\theta^{2}}\left(e^{\theta t_{1}}-1-t_{1} \theta\right)\right\} \\
& =\frac{h D}{\theta^{2}}\left(e^{\theta t_{1}}-t_{1} \theta-1\right) \sum_{n=0}^{m-1} C(n T) \\
& =\frac{h D}{\theta^{2}}\left(e^{\theta t_{1}}-t_{1} \theta-1\right) \sigma \sum_{n=0}^{m-1}(1+k n t) \\
& =\frac{h D}{\theta^{2}}\left(e^{\theta t_{1}}-t_{1} \theta-1\right) C_{0}\left[m+\frac{K T(m)(m-1)}{2}\right] \\
& =\frac{C_{0} h D}{\theta^{2}}\left[e^{\theta t_{1}}-t_{1} \theta-1\right] m\left[1+\frac{K T(m-1)}{2}\right] \\
& =\frac{m C_{0} h D}{\theta^{2}}\left[1+\theta t_{1}+\frac{\theta^{2} t_{1}^{2}}{2}+\frac{\theta^{3} t_{1}^{3}}{6}+\ldots \ldots . .-\theta t_{1}-1\right]\left[1+\frac{K T(m-1)}{2}\right] \\
& =\frac{m C_{0} h D}{\theta^{2}}\left[\frac{\theta^{2} t_{1}^{2}}{2}+\frac{\theta^{3} t_{1}^{3}}{6}+\ldots \ldots . .\right]\left[1+\frac{K T(m-1)}{2}\right] \\
& =m C_{0} h D\left[\frac{t_{1}^{2}}{2}+\frac{\theta t_{1}^{3}}{6}\right]\left[1+\frac{K T(m-1)}{2}\right] \\
& =m C_{0} h D\left[\frac{t_{1}^{2}}{2}+\frac{\theta t_{1}^{3}}{6}\right]\left[1+\frac{K T(m-1)}{2}\right] \\
& \text { Now } \frac{t_{1}^{2}}{2}+\frac{\theta t_{1}^{3}}{6}=\frac{1}{2}\left[\left[\frac{Q-S}{D}-\frac{\theta(Q-S)^{2}}{2 D^{2}}\right]^{2}\right]+\frac{\theta(Q-S)^{3}}{6 D^{3}} \\
& \frac{1}{2} \frac{\theta(Q-S)^{2}}{D^{2}}+\frac{1}{2} \frac{\theta^{2}(Q-S)^{4}}{4 D^{2}}-\frac{\theta(Q-S)^{3}}{2 D^{3}}+\frac{\theta(Q-S)^{3}}{6 D^{3}} \\
& \approx \frac{(Q-S)^{2}}{2 D^{2}}-\frac{1}{3} \frac{\theta(Q-S)^{3}}{D^{3}} \\
& \Rightarrow \frac{t_{1}^{2}}{2}+\frac{\theta t_{1}^{3}}{6} \approx \frac{(Q-S)^{2}}{2 D^{2}}-\frac{\theta(Q-S)^{3}}{3 D^{3}} \\
& \text { Hence } C_{h}=m C_{0} h D\left[\frac{(Q-S)}{2 D^{2}}-\frac{\theta(Q-S)^{3}}{3 D^{3}}\right]\left[1+\frac{K T(m-1)}{2}\right] \\
& \frac{m C_{0} h D(Q-S)^{2}}{2 D^{2}}\left[1-\frac{2 \theta(Q-S)}{3 D}\right]\left[1+\frac{K T(m-1)}{2}\right] \\
& C_{h}=\frac{m C_{0} h(Q-S)^{2}}{2 D}\left[1-\frac{2 \theta(Q-S)}{3 D}\right]\left[1+\frac{K T(m-1)}{2}\right]
\end{aligned}
$$




$$
\begin{aligned}
& C_{i}=i_{C} \sum_{n=0}^{m-1} C(n T) \int_{\mu}^{t_{1}} I_{1}(t) d t \\
& =i_{c} \sum_{n=0}^{m-1} C_{0}(1+K n T) \int \frac{D}{\theta}\left[e^{\theta\left(t_{1}-t\right)}-1\right] d t \\
& =\frac{i_{C} C_{0} D}{\theta}\left[m+\frac{K T(m-1)(m)}{2}\right]\left[-\frac{1}{\theta}-t_{1}+\frac{e^{\theta\left(t_{1}-t\right)^{4}}}{\theta}+M\right] \\
& =\frac{i_{C} C_{0} D m}{\theta^{2}}\left[m+\frac{K T(m-1)(m)}{2}\right]\left[\theta M+e^{\theta\left(t_{1}-M\right)}-\theta t_{1}-1\right] \\
& =\frac{i_{C} C_{0} D m}{\theta^{2}}\left[m+\frac{K T(m-1)(m)}{2}\right]\left[1+\theta\left(t_{1}-M\right)+\frac{\theta^{2}\left(t_{1}-M\right)^{2}}{2}+\ldots \ldots \ldots .+\theta M-\theta t_{1}-1\right] \\
& =\frac{i_{c} C_{0} D}{\theta^{2}}\left[\frac{\theta^{2}\left(t_{1}-M\right)^{2}}{2}+\frac{\theta^{3}\left(t_{1}-M\right)^{3}}{6}+\ldots . . .\right]\left[1 \frac{K T(m-1)}{2}\right] \\
& =i_{c} C_{0} D M\left[\frac{\left(t_{1}-M\right)^{2}}{2}+\frac{1}{6} \theta\left(t_{1}-M\right)^{3}\right]\left[1+\frac{K T(m-1)}{2}\right] \ldots . . . \text { neglect } \theta^{2}, \theta^{3} \ldots . \\
& C_{i}=i_{e} C_{0} D M\left[\frac{1}{2}\left(t_{1}-M^{2}\right)+\frac{1}{6}\left(t_{1}-M\right)^{3} \theta\right]\left[1+\frac{K T}{2}(m-1)\right]
\end{aligned}
$$

But we know that

$$
\begin{aligned}
& t_{1}=\frac{Q-S}{D}=\frac{\theta(Q-S)^{2}}{2 D^{2}} \\
& \Rightarrow\left(t_{1}-M\right)=\frac{Q-S}{D}-\frac{\theta(Q-S)^{2}}{2 D^{2}}-M \\
& =\frac{Q-S-M D}{D}-\frac{\theta(Q-S)^{2}}{2 D^{2}} \\
& \Rightarrow\left(t_{1}-M\right)^{2}=\left\{\frac{Q-S-M D}{D}-\frac{\theta(Q-S)^{2}}{2 D^{2}}\right\}^{2} \\
& \approx\left\{\frac{\left(Q-S-M D^{2}\right)}{D^{2}}-\frac{\theta(Q-S-M D)(Q-S)^{2} \theta}{D^{3}}\right\}
\end{aligned}
$$

Neglect higher part of $\theta$

$$
\begin{aligned}
& \left(t_{1}-M\right)^{3}=\left\{\frac{Q-S-M D}{D}-\frac{\theta(Q-S)^{2}}{2 D^{2}}\right\}^{3} \\
& \approx \frac{(Q-S-M D)^{3}}{D^{3}}-\frac{3 \theta(Q-S-M D)^{2}(Q-S)^{2}}{2 D^{4}}
\end{aligned}
$$

Hence $\frac{1}{2}\left(t_{1}-M\right)^{2}+\frac{\theta}{6}\left(t_{1}-M\right)^{3}$

$$
\begin{aligned}
& \frac{1}{2} \frac{(Q-S-M D)^{2}}{D^{2}}-\frac{1}{2} \frac{(Q-S-M D)(Q-S)^{2} \theta}{D^{3}} \\
& +\frac{\theta}{6} \frac{(Q-S-M D)^{3}}{D^{3}}-\frac{\theta}{6} \frac{3 \theta(Q-S-M D)^{2}(Q-S)^{2}}{2 D^{4}} \\
& =\frac{Q-S-M D}{2 D}\left[\frac{(Q-S-M D)}{D}-\frac{(Q-S)^{2} \theta}{D^{2}}+\frac{\theta}{3} \frac{(Q-S-M D)^{2}}{D^{2}}\right]
\end{aligned}
$$




$$
\begin{aligned}
& \quad \frac{Q-S-M D}{2 D}\left[\frac{Q-S}{D}-M-\theta\left\{\frac{(Q-S)^{2}}{D^{2}}-\frac{1}{3}\left(\frac{Q-S}{D}-M\right)^{2}\right\}\right] \\
& \text { Hence } C_{i}=m C_{0} i_{C} i_{C} D\left\{\frac{1}{2}\left(t_{1}-M\right)^{2}+\frac{\theta}{6}\left(t_{1}-M\right)^{3}\right\}\left\{1+\frac{K T}{2}(m-1)\right\} \\
& \Rightarrow C_{i}=M C_{0} i_{c} D \frac{(Q-S-M D)}{2 D}\left[\frac{Q-S}{D}-M-\theta\left\{\frac{(Q-S)^{2}}{D^{2}}-\frac{1}{3}\left(\frac{Q-S}{D}-M\right)^{2}\right\}\left[1+\frac{K T}{2}(m-1)\right]\right. \\
& \Rightarrow C_{i}=\frac{M C_{0} i_{C}(Q-S-M D)}{2}\left[\frac{Q-S}{D}-M-\theta\left\{\frac{2}{3} \frac{(Q-S)^{2}}{D^{2}}\right\}+\frac{2}{3} \frac{m(Q-S)}{D}-\frac{M^{2}}{3}\right]\left[1+\frac{K T}{2}(m-1)\right] \\
& \text { Hence } \Rightarrow C_{i}=\frac{i_{C} M C_{0}}{2}(Q-S-M D)\left[\frac{Q-S-M D}{D}-\theta\left\{\frac{2(Q-S)(Q-S+M D)}{3 D^{2}}-\frac{M^{2}}{3}\right\}\right]\left[1+\frac{K T}{2}(m-1)\right]
\end{aligned}
$$

\begin{tabular}{|c|c|c|c|c|c|c|c|c|c|c|c|}
\hline \multicolumn{12}{|c|}{ Case A1 } \\
\hline Parameter & Value & Iteration & $\mathrm{S}$ & $\mathbf{m}$ & $\mathbf{T}$ & $t_{1}$ & $\mathbf{Q}$ & $\rho$ & PE & TC & TC\% \\
\hline \multirow[t]{3}{*}{$\mathbf{A}_{0}$} & 7.1 & 64 & 0 & 2 & 0.5 & 0.5 & 150.1804 & 1 & 0 & 807.202 & .111314473 \\
\hline & 7.4 & 66 & 0 & 2 & 0.5 & 0.5 & 150.1804 & 1 & 0 & 808.2952 & .027828618 \\
\hline & 7.6 & 64 & 0 & 2 & 0.5 & 0.5 & 150.1804 & 1 & 0 & 808.7452 & .027 \\
\hline \multirow[t]{3}{*}{$\mathrm{C}_{0}$} & 2.4 & 65 & 0 & 2 & 0.5 & 0.5 & 150.1804 & 1 & 0 & 776.8544 & 3.9165 \\
\hline & 2.6 & 65 & 0 & 2 & 0.5 & 0.5 & 150.1804 & 1 & 0 & 840.1860 & 3.9165 \\
\hline & 2.7 & 69 & 0 & 2 & 0.5 & 0.5 & 150.1804 & 1 & 0 & 871.8579 & 7.8330 \\
\hline \multirow[t]{3}{*}{$\mathbf{M}_{1}$} & 0.20 & 60 & 0 & 2 & 0.5 & 0.5 & 100.0801 & 0.99999 & 0 & 539.3365 & 33.2933 \\
\hline & 0.21 & 59 & 0 & 2 & 0.5 & 0.5 & 105.0883 & 1 & 0 & 566.0160 & 29.9935 \\
\hline & 0.22 & 59 & 0 & 2 & 0.5 & 0.5 & 110.0970 & 1 & 0 & 592.7486 & 26.6872 \\
\hline \multirow[t]{3}{*}{$\mathbf{I}_{\mathrm{C}}$} & 0.1101 & 64 & 0 & 2 & 0.5 & 0.5 & 150.1804 & 1 & 0 & 808.5202 & 0 \\
\hline & 0.1102 & 64 & 0 & 2 & 0.5 & 0.5 & 150.1804 & 1 & 0 & 808.5202 & 0 \\
\hline & 0.1105 & 64 & 0 & 2 & 0.5 & 0.5 & 150.1804 & 1 & 0 & 808.5202 & 0 \\
\hline \multirow[t]{3}{*}{$\mathbf{I}_{\mathrm{e}}$} & 0.08 & 49 & 0 & 2 & 0.5 & 0.5 & 150.1804 & 1 & 0 & 816.9577 & 1.0435 \\
\hline & 0.10 & 69 & 0 & 2 & 0.5 & 0.5 & 150.1804 & 1 & 0 & 800.0827 & 1.0435 \\
\hline & 0.101 & 69 & 0 & 2 & 0.5 & 0.5 & 150.1804 & 1 & 0 & 799.2390 & 1.1479 \\
\hline \multirow[t]{3}{*}{ D } & 480 & 64 & 0 & 2 & 0.5 & 0.5 & 144.1732 & 1 & 0 & 776.8544 & 3.9165 \\
\hline & 481 & 64 & 0 & 2 & 0.5 & 0.5 & 144.4736 & 1 & 0 & 778.4377 & 3.7206 \\
\hline & 482 & 64 & 0 & 2 & 0.5 & 0.5 & 144.7739 & 1 & 0 & 780.0210 & 3.5248 \\
\hline \multirow[t]{3}{*}{ h } & 0.14 & 65 & 0 & 2 & 0.5 & 0.5 & 150.1804 & 1 & 0 & 803.4496 & 0.6271 \\
\hline & 0.16 & 64 & 0 & 2 & 0.5 & 0.5 & 150.1804 & 1 & 0 & 805.9849 & 0.3135 \\
\hline & 0.20 & 64 & 0 & 2 & 0.5 & 0.5 & 150.1804 & 1 & 0 & 811.0555 & 0.3135 \\
\hline \multirow[t]{3}{*}{$\mathbf{H}$} & 1.1 & 66 & 0 & 2 & 0.5 & 0.5 & 150.1804 & 1 & 0 & 817.5038 & 1.1111 \\
\hline & 1.101 & 66 & 0 & 2 & 0.5 & 0.5 & 150.1804 & 1 & 0 & 817.5936 & 1.1222 \\
\hline & 1.102 & 66 & 0 & 2 & 0.5 & 0.5 & 150.1804 & 1 & 0 & 817.6535 & 1.1333 \\
\hline \multirow[t]{3}{*}{$\mathbf{K}$} & 0.49 & 66 & 0 & 2 & 0.5 & 0.5 & 150.1804 & 1 & 0 & 806.7235 & 0.2222 \\
\hline & 0.51 & 64 & 0 & 2 & 0.5 & 0.5 & 150.1804 & 1 & 0 & 810.3169 & 0.2222 \\
\hline & 0.52 & 68 & 0 & 2 & 0.5 & 0.5 & 150.1804 & 1 & 0 & 812.1137 & 0.4444 \\
\hline \multirow[t]{3}{*}{$\theta$} & 0.002 & 65 & 0 & 2 & 0.5 & 0.5 & 150.1804 & 1 & 0 & 807.9939 & 0.0650 \\
\hline & 0.003 & 65 & 0 & 2 & 0.5 & 0.5 & 150.1804 & 1 & 0 & 808.2569 & 0.0325 \\
\hline & 0.005 & 66 & 0 & 2 & 0.5 & 0.5 & 150.1804 & 1 & 0 & 808.7839 & 0.0326 \\
\hline \multirow[t]{3}{*}{$\mathrm{S}_{0}$} & 0.2 & 64 & 0 & 2 & 0.5 & 0.5 & 150.1804 & 1 & 0 & 808.5202 & 0 \\
\hline & 0.3 & 64 & 0 & 2 & 0.5 & 0.5 & 150.1804 & 1 & 0 & 808.5202 & 0 \\
\hline & 0.4 & 64 & 0 & 2 & 0.5 & 0.5 & 150.1804 & 1 & 0 & 808.5202 & 0 \\
\hline \multirow[t]{3}{*}{$K_{1}$} & 0.5 .1 & 64 & 0 & 2 & 0.5 & 0.5 & 150.1804 & 1 & 0 & 808.5202 & \\
\hline & 0.5 .0 .5 & 60.5 & 0 & 2 & 0.5 & 0.5 & 150.1804 & 1 & 0 & 808.5202 & \\
\hline & 0.5 .4 & 70 & 0 & 2 & 0.5 & 0.5 & 150.1804 & 1 & 0 & 808.5202 & \\
\hline \multirow[t]{3}{*}{$\alpha_{1}$} & 1.1 & 56 & 0 & 2 & 0.5 & 0.5 & 150.1804 & 1 & 0 & 808.5202 & 0 \\
\hline & 1.2 & 56 & 0 & 2 & 0.5 & 0.5 & 150.1804 & 1 & 0 & 808.5202 & 0 \\
\hline & 1.3 & 55 & 0 & 2 & 0.5 & 0.5 & 150.1804 & 1 & 0 & 808.5202 & 0 \\
\hline
\end{tabular}

\section{Appendix -B}


Case A2 $M=t_{1}$

\begin{tabular}{|c|c|c|c|c|c|c|c|c|c|c|c|}
\hline Parameter & Value & Iteration & $\mathrm{S}$ & M & $\mathbf{T}$ & $\mathbf{t}_{1}$ & $\mathbf{Q}$ & $\rho$ & PE & TC & TC\% \\
\hline \multirow[t]{3}{*}{$\mathbf{A}_{\mathbf{0}}$} & 7.1 & 101 & 64.56014 & 2.330349 & 0.4291203 & 0.3 & 214.7406 & 1 & 0 & 1401.334 & 0.0752 \\
\hline & 7.4 & 98 & 67.63357 & 2.297440 & 0.4352671 & 0.3 & 217.8140 & 1 & 0 & 1402.127 & 0.0186 \\
\hline & 7.6 & 67 & 69.69357 & 2.275897 & 0.4393871 & 0.3 & 219.8740 & 1 & 0 & 1402.649 & 0.0185 \\
\hline \multirow[t]{3}{*}{$\mathrm{C}_{0}$} & 2.4 & 99 & 71.89285 & 2.253340 & 0.4437857 & 0.3 & 222.0733 & 1 & 0 & 1347.069 & 3.9446 \\
\hline & 2.6 & 67 & 65.70061 & 2.318028 & 0.4314012 & 0.3 & 215.8810 & 1 & 0 & 1457.696 & 3.9437 \\
\hline & 2.7 & 70 & 62.97371 & 2.347708 & 0.4259474 & 0.3 & 213.1541 & 1 & 0 & 1512.992 & 7.8867 \\
\hline \multirow[t]{3}{*}{$\mathbf{M}_{1}$} & 0.21 & 82 & 1.376093 & 4.700304 & 0.2127522 & 0.21 & 106.4644 & 1 & 0 & 1434.503 & 2.2899 \\
\hline & 0.22 & 86 & 7.979468 & 4.238026 & 0.2359589 & 0.22 & 118.0764 & 1 & 0 & 1430.872 & 2.0310 \\
\hline & 0.23 & 126 & 14.80668 & 3.857882 & 0.22596134 & 0.23 & 129.9127 & 1 & 0 & 1427.274 & 1.7744 \\
\hline \multirow[t]{3}{*}{$\mathbf{I}_{\mathbf{C}}$} & 0.1101 & 67 & 68.66241 & 2.286630 & 0.4373248 & 0.3 & 218.8428 & 1 & 0 & 1402.389 & 0 \\
\hline & 0.1102 & 67 & 68.60241 & 2.286630 & 0.4373248 & 0.3 & 218.8428 & 1 & 0 & 1402.389 & 0 \\
\hline & 0.1105 & 67 & 68.66241 & 2.286630 & 0.4373248 & 0.3 & 218.8428 & 1 & 0 & 1402.389 & 0 \\
\hline \multirow[t]{3}{*}{$\mathbf{I}_{\mathbf{e}}$} & 0.10 & 72 & 31.03489 & 2.781898 & 0.3620698 & 0.3 & 181.2153 & 1 & 0 & 1391.557 & 0.7723 \\
\hline & 0.101 & 77 & 27.31384 & 2.819859 & 0.3546277 & 0.3 & 177.4943 & 1 & 0 & 1390.342 & 0.8590 \\
\hline & 0.102 & 84 & 23.58782 & 2.880386 & 0.3471756 & 0.3 & 173.7683 & 1 & 0 & 1389.100 & 0.9475 \\
\hline \multirow[t]{3}{*}{ D } & 480 & 86 & 69.01714 & 2.253340 & 0.4437857 & 0.3 & 213.1904 & 1 & 0 & 1347.009 & 3.9489 \\
\hline & 481 & 91 & 68.99882 & 2.255052 & 0.4434487 & 0.3 & 213.4724 & 1 & 0 & 1347.836 & 3.7473 \\
\hline & 482 & 103 & 68.98058 & 2.256760 & 0.4431132 & 0.3 & 213.7545 & 1 & 0 & 1352.602 & 3.5501 \\
\hline \multirow[t]{3}{*}{$\mathbf{h}$} & 0.10 & 63 & 23.51602 & 2.881578 & 0.3470320 & 0.3 & 173.6964 & 1 & 0 & 1389.076 & 0.9493 \\
\hline & 0.11 & 63 & 29.11212 & 2.791548 & 0.3582242 & 0.3 & 179.2925 & 1 & 0 & 1390.933 & 0.8168 \\
\hline & 0.12 & 63 & 34.70035 & 2.707087 & 0.3644007 & 0.3 & 184.8808 & 1 & 0 & 1392.728 & 0.6888 \\
\hline \multirow[t]{3}{*}{$\mathbf{H}$} & 1.1 & 68 & 59.95580 & 2.619599 & 0.4199116 & 0.3 & 210.1362 & 1 & 0 & 1576.328 & 12.4030 \\
\hline & 1.101 & 91 & 59.87780 & 2.622955 & 0.4197556 & 0.3 & 210.0582 & 1 & 0 & 1578.097 & 12.5291 \\
\hline & 1.102 & 91 & 59.87780 & 2.622955 & 0.4197556 & 0.3 & 210.0582 & 1 & 0 & 1578.097 & 12.5291 \\
\hline \multirow[t]{3}{*}{$\mathbf{K}$} & 0.49 & 66 & 61.41694 & 2.364995 & 0.4228339 & 0.3 & 211.5974 & 1 & 0 & $1398 . .858$ & 0.2517 \\
\hline & 0.51 & 65 & 77.15393 & 2.201151 & 0.4543079 & 0.3 & 227.3344 & 1 & 0 & 1405.842 & 0.2462 \\
\hline & 0.52 & 94 & 87.51674 & 2.105115 & 0.4750335 & 0.3 & 237.6972 & 1 & 0 & 1409.203 & 0.4858 \\
\hline \multirow[t]{3}{*}{$\boldsymbol{\theta}$} & 0.002 & 65 & 66.25897 & 2.312043 & 0.4325179 & 0.3 & 216.3491 & 1 & 0 & 1401.775 & .0437 \\
\hline & 0.003 & 65 & 67.45845 & 2.299290 & 0.4349169 & 0.3 & 217.5937 & 1 & 0 & 1402.082 & .0218 \\
\hline & 0.005 & 63 & 69.87101 & 2.274061 & 0.4397420 & 0.3 & 220.0967 & 1 & 0 & 1402.693 & .0216 \\
\hline \multirow[t]{3}{*}{$\mathrm{S}_{0}$} & 0.6 & 60 & 36.57086 & 2.679947 & 0.3731417 & 0.3 & 186.7513 & 1 & 0 & 1404.381 & 0.1420 \\
\hline & 0.7 & 63 & 25.40634 & 2.850524 & 0.3508127 & 0.3 & 175.5868 & 1 & 0 & 1405.220 & 0.2018 \\
\hline & 0.8 & 63 & 19.53628 & 2.949221 & 0.3390726 & 0.3 & 169.7167 & 1 & 0 & 1405.693 & 0.2355 \\
\hline \multirow[t]{3}{*}{$K_{1}$} & 2.1 & 67 & 68.66241 & 2.286630 & 0.4373248 & 0.3 & 218.8428 & 1 & 0 & 1402.389 & 0 \\
\hline & 2.2 & 67 & 68.66241 & 2.286630 & 0.4373248 & 0.3 & 218.8428 & 1 & 0 & 1402.384 & 0 \\
\hline & 2.4 & 67 & 68.66241 & 2.286630 & 0.4373248 & 0.3 & 218.8428 & 1 & 0 & 1402.389 & 0 \\
\hline \multirow[t]{3}{*}{$\alpha_{1}$} & 1.1 & 66 & 68.66241 & 2.286630 & 0.4373248 & 0.3 & 218.8428 & 1 & 0 & 1402.389 & 0 \\
\hline & 1.2 & 68 & 68.66241 & 2.286630 & 0.4373248 & 0.3 & 218.8428 & 1 & 0 & 1402.389 & 0 \\
\hline & 1.3 & 77 & 68.66241 & 2.286630 & 0.4373248 & 0.3 & 218.8428 & 1 & 0 & 1402.389 & 0 \\
\hline
\end{tabular}

Case A3 $\mathbf{t}_{1}<\mathbf{M}_{1}<\mathbf{T}$

\begin{tabular}{|c|c|c|c|c|c|c|c|c|c|c|c|}
\hline Parameter & Value & Iteration & $\mathbf{S}$ & $\mathbf{M}$ & $\mathbf{T}$ & $\mathbf{t}_{\mathbf{1}}$ & $\mathbf{Q}$ & $\mathbf{\rho}$ & $\mathbf{P E}$ & $\mathbf{T C}$ & $\mathbf{T C} \%$ \\
\hline $\mathbf{A}_{\mathbf{0}}$ & 7.1 & 74 & 64.56013 & 2.330349 & 0.4291203 & 0.3 & 214.7406 & 1 & 0 & 1401.334 & 0.07522 \\
\hline & 7.4 & 66 & 67.63357 & 2.297440 & 0.4352671 & 0.3 & 217.8140 & 1 & 0 & 1402.127 & 0.0186 \\
\hline & 7.6 & 68 & 69.69357 & 2.275897 & 0.4352671 & 0.3 & 219.8740 & 1 & 0 & 1402.649 & 0.0185 \\
\hline $\mathbf{C}_{\mathbf{0}}$ & 2.4 & 68 & 71.89285 & 2.253340 & 0.4437857 & 0.3 & 222.0733 & 1 & 0 & 1374.069 & 3.9446 \\
\hline & 2.6 & 69 & 65.70061 & 2.318028 & 0.4314012 & 0.3 & 215.8810 & 1 & 0 & 1457.696 & 3.9437 \\
\hline & 2.7 & 74 & 62.97371 & 2.347708 & 0.4259474 & 0.3 & 213.1541 & 1 & 0 & 1512.992 & 7.8867 \\
\hline $\mathbf{M}_{\mathbf{1}}$ & 0.31 & 91 & 77.37351 & 2.151708 & 0.464770 & 0.3 & 232.5661 & 1 & 0 & 1398.828 & 0.2539 \\
\hline & 0.311 & 71 & 78.26252 & 2.138923 & 0.4675250 & 0.3 & 233.9564 & 1 & 0 & 1398.472 & 0.2793 \\
\hline & 0.32 & 70 & 86.42348 & 2.029027 & 0.4928470 & 0.3 & 246.6288 & 1 & 0 & 1395.259 & 0.5084 \\
\hline $\mathbf{I}_{\mathbf{C}}$ & 0.1101 & 69 & 68.66241 & 2.286630 & 0.4373248 & 0.3 & 218.8425 & 1 & 0 & 1402.389 & 0 \\
\hline & 0.1102 & 64 & 68.66241 & 2.286630 & 0.4373248 & 0.3 & 218.8425 & 1 & 0 & 1402.389 & 0 \\
\hline & 0.1103 & 69 & 68.66241 & 2.286630 & 0.4373248 & 0.3 & 218.8425 & 1 & 0 & 1402.389 & 0 \\
\hline $\mathbf{I}_{\mathbf{e}}$ & 0.10 & 67 & 31.03489 & 2.761898 & 0.3620698 & 0.3 & 181.2153 & 1 & 0 & 1391.557 & 0.7723 \\
\hline & 0.101 & 62 & 27.31384 & 2.819859 & 0.3546277 & 0.3 & 177.4943 & 1 & 0 & 1390.342 & 0.8590 \\
\hline & 0.102 & 70 & 23.58782 & 2.880386 & 0.3471756 & 0.3 & 173.7683 & 1 & 0 & 1398.100 & 0.9475 \\
\hline $\mathbf{D}$ & 480 & 75 & 69.01714 & 2.253340 & 0.4437857 & 0.3 & 213.1904 & 1 & 0 & 1347.069 & 3.9489 \\
\hline & 481 & 66 & 68.99882 & 2.255052 & 0.4434487 & 0.3 & 213.4724 & 1 & 0 & 1349.836 & 3.7473 \\
\hline & 482 & 80 & 68.98058 & 2.256760 & 0.4431132 & 0.3 & 213.7545 & 1 & 0 & 1352.602 & 3.5501 \\
\hline
\end{tabular}




\begin{tabular}{|c|c|c|c|c|c|c|c|c|c|c|c|}
\hline $\mathbf{h}$ & 0.14 & 61 & 45.89491 & 2.552389 & 0.3917898 & 0.3 & 196.0753 & 1 & 0 & 1396.148 & 0.4450 \\
\hline & 0.16 & 60 & 57.18474 & 20413305 & 0.4143695 & 0.3 & 207.3652 & 1 & 0 & 1399.362 & 0.2158 \\
\hline & 0.19 & 67 & 74.50468 & 2.227125 & 0.4490094 & 0.3 & 224.6851 & 1 & 0 & 1403.837 & 0.1032 \\
\hline $\mathbf{H}$ & 1.1 & 69 & 59.95580 & 2.619599 & 0.4149116 & 0.3 & 210.1362 & 1 & 0 & 1576.328 & 12.4030 \\
\hline & 1.101 & 69 & 59.87780 & 2.622955 & 0.4197556 & 0.3 & 210.0582 & 1 & 0 & 1578.097 & 12.5291 \\
\hline & 1.102 & 72 & 59.79995 & 2.626311 & 0.4195999 & 0.3 & 209.9804 & 1 & 0 & 1579.868 & 12.6554 \\
\hline $\mathbf{K}$ & 0.49 & 74 & 61.41694 & 2.364995 & 0.4228339 & 0.3 & 211.5974 & 1 & 0 & 1398.858 & 0.2517 \\
\hline & 0.51 & 68 & 77.15393 & 2.201151 & 0.4543079 & 0.3 & 227.3344 & 1 & 0 & 1405.842 & 0.2462 \\
\hline & 0.52 & 68 & 87.51674 & 2.105115 & 0.4750335 & 0.3 & 237.6972 & 1 & 0 & 1409.203 & 0.4858 \\
\hline $\boldsymbol{\theta}$ & 0.002 & 68 & 66.25897 & 2.312043 & 0.4325179 & 0.3 & 216.3491 & 1 & 0 & 1401.775 & 0.0437 \\
\hline & 0.003 & 68 & 67.45845 & 2.299240 & 0.4349169 & 0.3 & 217.5937 & 1 & 0 & 1402.082 & 0.0218 \\
\hline & 0.005 & 68 & 69.87101 & 2.274061 & 0.4397420 & 0.3 & 220.0967 & 1 & 0 & 1402.693 & 0.0216 \\
\hline $\mathbf{S}_{\mathbf{0}}$ & 0.51 & 68 & 62.7222 & 2.350483 & 0.4254444 & 0.3 & 212.9027 & 1 & 0 & 1402.711 & 0.0229 \\
\hline & 0.53 & 67 & 53.78680 & 2.453545 & 0.4075736 & 0.3 & 203.9672 & 1 & 0 & 1403.235 & 0.0603 \\
\hline & 0.54 & 67 & 50.30232 & 2.496277 & 0.4006046 & 0.3 & 200.4828 & 1 & 0 & 1403.453 & 0.0758 \\
\hline $\mathbf{K}_{\mathbf{1}}$ & 2.1 & 66 & 68.66241 & 2.286630 & 0.4373248 & 0.3 & 218.8428 & 1 & 0 & 1402.389 & 0 \\
\hline & 2.2 & 68 & 68.66241 & 2.286630 & 0.4373248 & 0.3 & 218.8428 & 1 & 0 & 1402.389 & 0 \\
\hline & 2.4 & 67 & 68.66241 & 2.286630 & 0.4373248 & 0.3 & 218.8428 & 1 & 0 & 1402.389 & 0 \\
\hline $\boldsymbol{\alpha}_{\mathbf{1}}$ & 1.1 & 65 & 68.66241 & 2.286630 & 0.4373248 & 0.3 & 218.8428 & 1 & 0 & 1402.389 & 0 \\
\hline & 1.11 & 80 & 68.66241 & 2.286630 & 0.4373248 & 0.3 & 218.8428 & 1 & 0 & 1402.389 & 0 \\
\hline & 1.12 & 64 & 68.66241 & 2.286630 & 0.4373248 & 0.3 & 218.8428 & 1 & 0 & 1402.389 & 0 \\
\hline
\end{tabular}

\begin{tabular}{|c|c|c|c|c|c|c|c|c|c|c|c|}
\hline \multicolumn{12}{|c|}{ Case B1 $\mathbf{M}_{1}<\mathrm{t}_{1}$} \\
\hline Parameter & Value & Iteration & $\mathrm{S}$ & $\mathbf{m}$ & $T$ & $t_{1}$ & $\mathbf{Q}$ & $\rho$ & PE & TC & TC\% \\
\hline \multirow[t]{3}{*}{$\mathbf{A}_{0}$} & 7.1 & 21 & 0 & 2 & 0.5 & 0.5 & 150.1804 & 3 & 4000 & 4807.620 & 0.018716777 \\
\hline & 7.4 & 21 & 0 & 2 & 0.5 & 0.5 & 150.1804 & 3 & 4000 & 4808.295 & 4.67919443 \\
\hline & 7.6 & 21 & 0 & 2 & 0.5 & 0.5 & 150.1804 & 3 & 4000 & 4808.745 & 4.67919443 \\
\hline \multirow[t]{3}{*}{$\mathrm{C}_{0}$} & 2.4 & 21 & 0 & 2 & 0.5 & 0.5 & 150.1804 & 3 & 4000 & 4776.854 & 1.369526228 \\
\hline & 2.6 & 21 & 0 & 2 & 0.5 & 0.5 & 150.1804 & 3 & 4000 & 4840.186 & 0.658539425 \\
\hline & 2.7 & 21 & 0 & 2 & 0.5 & 0.5 & 150.1804 & 3 & 4000 & 4871.852 & 1.317078852 \\
\hline \multirow[t]{3}{*}{$\mathbf{M}_{1}$} & 0.21 & 24 & 0 & 2 & 0.5 & 0.5 & 105.0883 & 3 & 4000 & 4568.016 & 5.04321496 \\
\hline & 0.22 & 24 & 0 & 2 & 0.5 & 0.5 & 110.0973 & 3 & 4000 & 4592.749 & 0.044872642 \\
\hline & 0.23 & 24 & 0 & 2 & 0.5 & 0.5 & 115.1060 & 3 & 4000 & 4619.534 & 3.930232171 \\
\hline \multirow[t]{3}{*}{$\mathbf{I}_{\mathrm{C}}$} & 0.1101 & 21 & 0 & 2 & 0.5 & 0.5 & 150.1804 & 3 & 4000 & 4808.520 & 0 \\
\hline & 0.1102 & 21 & 0 & 2 & 0.5 & 0.5 & 150.1804 & 3 & 4000 & 4808.520 & 0 \\
\hline & 0.1105 & 21 & 0 & 2 & 0.5 & 0.5 & 150.1804 & 3 & 4000 & 4808.520 & 0 \\
\hline \multirow[t]{3}{*}{$I_{e}$} & 0.100 & 21 & 0 & 2 & 0.5 & 0.5 & 150.1804 & 3 & 4000 & 4800.083 & 0.175459392 \\
\hline & 0.101 & 21 & 0 & 2 & 0.5 & 0.5 & 150.1804 & 3 & 4000 & 4799.239 & 0.193011571 \\
\hline & 0.102 & 21 & 0 & 2 & 0.5 & 0.5 & 150.1804 & 3 & 4000 & 4798.395 & 0.210563749 \\
\hline \multirow[t]{3}{*}{ D } & 480 & 21 & 0 & 2 & 0.5 & 0.5 & 144.1732 & 3 & 3840 & 4616.854 & 3.985966576 \\
\hline & 481 & 21 & 0 & 2 & 0.5 & 0.5 & 144.4736 & 3 & 3848 & 4626.438 & 3.78665369 \\
\hline & 482 & 21 & 0 & 2 & 0.5 & 0.5 & 144.7739 & 3 & 3856 & 4636.021 & 3.5873616 \\
\hline \multirow[t]{3}{*}{ h } & 0.10 & 22 & 0 & 2 & 0.5 & 0.5 & 150.1804 & 3 & 4000 & 4798.379 & 0.210896492 \\
\hline & 0.11 & 22 & 0 & 2 & 0.5 & 0.5 & 150.1804 & 3 & 4000 & 4799.647 & 0.184526631 \\
\hline & 0.12 & 21 & 0 & 2 & 0.5 & 0.5 & 150.1804 & 3 & 4000 & 4800.914 & 0.158177568 \\
\hline \multirow[t]{3}{*}{$\mathbf{H}$} & 1.1 & 21 & 0 & 2 & 0.55 & 0.55 & 150.1804 & 3 & 4000 & 4817.504 & 0.186835034 \\
\hline & 1.101 & 21 & 0 & 2 & 0.5505 & 0.5505 & 150.1804 & 3 & 4000 & 4517.594 & 0.188706712 \\
\hline & 0.102 & 21 & 0 & 2 & 0.5 & 0.5510 & 150.1804 & 3 & 4000 & 4817.683 & 0.190557593 \\
\hline \multirow[t]{3}{*}{$\mathbf{K}$} & 0.49 & 21 & 0 & 2 & 0.5 & 0.5 & 150.1804 & 3 & 4000 & 4806.724 & 0.037350369 \\
\hline & 0.51 & 21 & 0 & 2 & 0.5 & 0.5 & 150.1804 & 3 & 4000 & 4810.317 & 0.037371166 \\
\hline & 0.52 & 21 & 0 & 2 & 0.5 & 0.5 & 150.1804 & 3 & 4000 & 4812.114 & 0.074742332 \\
\hline \multirow[t]{3}{*}{$\theta$} & 0.002 & 21 & 0 & 2 & 0.5 & 0.5 & 150.0901 & 3 & 4000 & 4807.994 & 0.010938916 \\
\hline & 0.003 & 21 & 0 & 2 & 0.5 & 0.5 & 150.1352 & 3 & 4000 & 4808.257 & 5.469458378 \\
\hline & 0.005 & 21 & 0 & 2 & 0.5 & 0.5 & 150.2257 & 3 & 4000 & 4808.784 & 5.490254798 \\
\hline \multirow[t]{3}{*}{$S_{0}$} & 0.6 & 21 & 0 & 2 & 0.5 & 0.5 & 150.1804 & 3 & 4000 & 4808.520 & 0 \\
\hline & 0.7 & 21 & 0 & 2 & 0.5 & 0.5 & 150.1804 & 3 & 4000 & 4808.520 & 0 \\
\hline & 0.8 & 21 & 0 & 2 & 0.5 & 0.5 & 150.1804 & 3 & 4000 & 4808.520 & 0 \\
\hline \multirow[t]{3}{*}{$K_{1}$} & 2.1 & 21 & 0 & 2 & 0.5 & 0.5 & 150.1804 & 3 & 4200 & 4808.520 & 4.159283938 \\
\hline & 2.2 & 21 & 0 & 2 & 0.5 & 0.5 & 150.1804 & 3 & 4400 & 4808.520 & 8.318567875 \\
\hline & 2.4 & 21 & 0 & 2 & 0.5 & 0.5 & 150.1804 & 3 & 4800 & 4808.520 & 16.63713575 \\
\hline \multirow[t]{3}{*}{$\alpha_{1}$} & 1.1 & 21 & 0 & 2 & 0.5 & 0.5 & 150.1804 & 3 & 7446.582 & 8255.103 & 7.167658656 \\
\hline & 1.2 & 21 & 0 & 2 & 0.5 & 0.5 & 150.1804 & 3 & 13862.900 & 14671.42 & 205.1130077 \\
\hline & 1.3 & 21 & 0 & 2 & 0.5 & 0.5 & 150.1804 & 3 & 25807.800 & 2616.32 & 45.58991124 \\
\hline
\end{tabular}


Case B2 = Case B3

\begin{tabular}{|c|c|c|c|c|c|c|c|c|c|c|c|}
\hline Parameter & Value & Iteration & $\mathrm{S}$ & m & $T$ & $t_{1}$ & $\mathbf{Q}$ & $\rho$ & PE & TC & TC\% \\
\hline \multirow[t]{3}{*}{$\mathbf{A}_{0}$} & 7.1 & 85 & 64.56014 & 2.330349 & 0.4291203 & 0.3 & 214.7406 & 2 & 1000 & 2401.334 & 0.043914619 \\
\hline & 7.4 & 84 & 67.63357 & 2.297440 & 0.4352671 & 0.3 & 217.8140 & 2 & 1000 & 2402.127 & 0.01090581 \\
\hline & 7.6 & 93 & 69.69357 & 2.275897 & 0.4393871 & 0.3 & 219.8740 & 2 & 1000 & 2402.649 & 0.01082256 \\
\hline \multirow[t]{3}{*}{$\mathrm{C}_{0}$} & 2.4 & 66 & 71.89285 & 2.253340 & 0.4437857 & 0.3 & 222.0733 & 2 & 1000 & 2347.069 & 2.302707846 \\
\hline & 2.6 & 111 & 65.70061 & 2.318028 & 0.4314012 & 0.3 & 215.8810 & 2 & 1000 & 2457.696 & 2.302166718 \\
\hline & 2.7 & 55 & 62.93371 & 2.347708 & 0.4259473 & 0.3 & 213.1541 & 2 & 1000 & 2512.992 & 4.603875559 \\
\hline \multirow[t]{3}{*}{$\mathbf{M}_{1}$} & 0.27 & 60 & 44.21128 & 2.790003 & 0.2584226 & 0.27 & 179.3574 & 2 & 1000 & 2413.038 & 0.141789445 \\
\hline & 0.28 & 80 & 52.10818 & 2.602700 & 0.3842764 & 0.28 & 192.2653 & 2 & 1000 & 2409.491 & 0.295622399 \\
\hline & 0.29 & 90 & 60.25077 & 2.436044 & 0.4105015 & 0.29 & 205.4194 & 2 & 1000 & 2405.942 & 0.443267097 \\
\hline \multirow[t]{3}{*}{$\mathbf{I}_{\mathbf{C}}$} & 0.1101 & 103 & 68.66241 & 2.286630 & 0.4373248 & 0.3 & 218.8428 & 2 & 1000 & 2402.389 & 0 \\
\hline & 0.1102 & 85 & 68.66241 & 2.286630 & 0.4373248 & 0.3 & 218.8428 & 2 & 1000 & 2402.389 & 0 \\
\hline & 0.1105 & 74 & 68.66241 & 2.286630 & 0.4373248 & 0.3 & 218.8428 & 2 & 1000 & 2402.389 & 0 \\
\hline \multirow[t]{3}{*}{$I_{e}$} & 0.100 & 73 & 31.034489 & 2.761898 & 0.3620698 & 0.3 & 181.2153 & 2 & 1000 & 2391.557 & 0.450884515 \\
\hline & 0.101 & 66 & 27.31384 & 2.819859 & 0.3546277 & 0.3 & 177.4943 & 2 & 1000 & 2390.342 & 0.501459172 \\
\hline & 0.103 & 71 & 19.85370 & 2.943710 & 0.3397074 & 0.3 & 170.0341 & 2 & 1000 & 2387.829 & 0.606063381 \\
\hline \multirow[t]{3}{*}{ D } & 480 & 63 & 69.01714 & 2.253340 & 0.4437857 & 0.3 & 213.1904 & 2 & 960 & 2307.069 & 3.967717135 \\
\hline & 481 & 69 & 68.99882 & 2.255052 & 0.4434487 & 0.3 & 231.4724 & 2 & 962 & 2311.836 & 3.769289653 \\
\hline & 482 & 65 & 68.98058 & 2.256760 & 0.4431132 & 0.3 & 213.4745 & 2 & 964 & 2316.602 & 3.570903796 \\
\hline \multirow[t]{3}{*}{ h } & 0.10 & 65 & 23.51602 & 2.881578 & 0.3470320 & 0.3 & 173.6964 & 2 & 1000 & 2389.076 & 0.554156716 \\
\hline & 0.11 & 74 & 29.11212 & 2.791548 & 0.3582242 & 0.3 & 179.2925 & 2 & 1000 & 2390.933 & 0.47685866 \\
\hline & 0.12 & 64 & 34.70035 & 2.707087 & 0.3694007 & 0.3 & 184.8808 & 2 & 1000 & 2392.728 & 0.402141368 \\
\hline \multirow[t]{3}{*}{ H } & 1.1 & 83 & 59.95580 & 2.619599 & 0.4199116 & 0.3 & 210.1362 & 2 & 1000 & 2576.320 & 7.239918265 \\
\hline & 1.101 & 98 & 59.87780 & 2.622955 & 0.4197556 & 0.3 & 210.0582 & 2 & 1000 & 2578.097 & 7.313844677 \\
\hline & 0.102 & 86 & 59.79995 & 2.626311 & 0.4195999 & 0.3 & 209.9804 & 2 & 1000 & 2579.868 & 7.387604589 \\
\hline \multirow[t]{3}{*}{$\mathbf{K}$} & 0.49 & 75 & 61.41694 & 2.364995 & 0.4228339 & 0.3 & 211.5974 & 2 & 1000 & 2398.585 & 0.146978695 \\
\hline & 0.51 & 70 & 77.15393 & 2.201151 & 0.4543079 & 0.3 & 227.3344 & 2 & 1000 & 2405.842 & 0.143731926 \\
\hline & 0.52 & 89 & 87.51674 & 2.105115 & 0.4750335 & 0.3 & 237.6972 & 2 & 1000 & 2409.203 & 0.283634332 \\
\hline \multirow[t]{3}{*}{$\theta$} & 0.002 & 92 & 66.25892 & 2.312043 & 0.43215179 & 0.3 & 216.3491 & 2 & 1000 & 2401.775 & 0.025557892 \\
\hline & 0.003 & 76 & 67.45845 & 2.299290 & 0.4349169 & 0.3 & 217.5937 & 2 & 1000 & 2402.082 & 0.012778946 \\
\hline & 0.005 & 80 & 69.87101 & 2.274061 & 0.4397420 & 0.3 & 220.0967 & 2 & 1000 & 2402.693 & 0.01265407 \\
\hline \multirow[t]{3}{*}{$S_{0}$} & 0.6 & 85 & 36.57086 & 2.679947 & 0.3731417 & 0.3 & 186.7513 & 2 & 1000 & 2404.381 & 0.082917462 \\
\hline & 0.7 & 77 & 25.40634 & 2.850524 & 0.3508127 & 0.3 & 175.5868 & 2 & 1000 & 2405.220 & 0.117841032 \\
\hline & 0.8 & 82 & 19.53628 & 2.949221 & 0.3390726 & 0.3 & 169.7167 & 2 & 1000 & 2405.693 & 0.137529767 \\
\hline \multirow[t]{3}{*}{$K_{1}$} & 2.1 & 75 & 68.66241 & 2.286630 & 0.4373248 & 0.3 & 218.8428 & 2 & 1050 & 2452.389 & 2.081261611 \\
\hline & 2.2 & 88 & 68.66241 & 2.286630 & 0.4373248 & 0.3 & 218.8428 & 2 & 1100 & 2452.389 & 4.162523222 \\
\hline & 2.4 & 70 & 68.66241 & 2.286630 & 0.4373248 & 0.3 & 218.8428 & 2 & 1200 & 2452.389 & 8.325046443 \\
\hline \multirow[t]{3}{*}{$\alpha_{1}$} & 1.1 & 79 & 68.66241 & 2.286630 & 0.4373248 & 0.3 & 218.8428 & 2 & 1861.000 & 3264.034 & 35.86617321 \\
\hline & 1.2 & 90 & 68.66241 & 2.286630 & 0.4373248 & 0.3 & 218.8428 & 2 & 3465.724 & 4868.113 & 102.633341 \\
\hline & 1.3 & 93 & 68.66241 & 2.286630 & 0.4373248 & 0.3 & 218.8428 & 2 & 6451.950 & 7854.339 & 226.386848 \\
\hline
\end{tabular}

